\title{
Influence of reinforcement arrangement in flexural fire behavior of hollow core slabs
}

\author{
José V. Aguado $^{\mathrm{a}}$, A. Espinos ${ }^{\mathrm{a}}$, A. Hospitaler ${ }^{\mathrm{a}}$, J.Ortega ${ }^{\mathrm{b}}$ and Manuel L. Romero ${ }^{\mathrm{a} *}$ \\ ${ }^{a}$ Instituto de Ciencia y Tecnología del Hormigón (ICITECH). Universitat Politècnica de \\ València, Spain. \\ ${ }^{\mathrm{b}}$ Centro Técnico del Fuego, AIDICO, Valencia, Spain.
}

\begin{abstract}
This paper describes four standard scale fire tests conducted on precast prestressed hollow core slabs under flexure. The influence of the reinforcement arrangement was investigated using two test parameters: the average axis distance (from 30.1 to $46.7 \mathrm{~mm}$ ), and the type of reinforcement ( $5 \mathrm{~mm}$ diameter wires and $9.5 \mathrm{~mm}$ diameter strands). An ISO 834 standard fire was applied maintaining the load level in a four-point test arrangement constant. The results presented different failure mechanisms, types of cracks, spalling patterns, and fire resistance ratings and it was shown that wires displayed optimal behavior as opposed to strands. A comparison was carried out with the current verification methods provided in Eurocode 2 part 1-2, and showed that verification methods tend to overestimate the calculation of fire resistance when both wire and strands are moved away from the exposed surface.
\end{abstract}

Keywords: fire resistance, hollow core slabs, precast construction, reinforcement

*Corresponding author: Tel: +34-963877007(ext:76742) Fax: +34-963879679, E-mail address: $\underline{\text { mromero@mes.upv.es }}$ 


\section{NOTATION}

HC Hollow core

FRR Fire Resistance Rating

EC2 Eurocode 2 Part 1-2 (EN 1992-1-2)

TDM Tabulated Data Method

500IM $\quad 500^{\circ} \mathrm{C}$ Isotherm Method

DfA Drilled from above

DfB Drilled from below

D Deflection limit from standard EN 1363

DR Deflection rate limit from standard EN 1363

$f_{c} \quad$ Compressive cylinder strength of concrete at room temperature (test date)

$f_{c t} \quad$ Tensile strength of concrete at room temperature (test date)

$f_{p, 0.1} \quad 0.1 \%$ proof-stress of prestressing steel at room temperature (test date)

$f_{p} \quad$ Tensile strength of steel at room temperature (test date)

$A_{p} \quad$ Total reinforcement area

$P_{\text {Test }} \quad$ Test load

$M_{\text {Test }} \quad$ Bending moment produced by the test load

$M_{R d, n o m} \quad$ Nominal ultimate bending moment at room temperature

$\mu_{\text {nom }} \quad$ Nominal load level

$M_{R d, \exp } \quad$ Experimental ultimate bending moment at room temperature

$\mu_{\exp } \quad$ Experimental load level

$a_{m} \quad$ Average axis distance

$\Delta a \quad$ Correction of the average axis distance

$\theta_{c r} \quad$ Critical temperature of steel reinforcement

$\gamma_{M, f i} \quad$ Partial security factor for materials in fire design

$F R R_{T D M} \quad$ Fire resistance rating from the Tabulated Data Method

$\varepsilon_{T D M} \quad$ Error ratio from the Tabulated Data Method

$F R R_{500 I M} \quad$ Fire resistance rating from the $500^{\circ} \mathrm{C}$ Isotherm Method

$\varepsilon_{500 \mathrm{M}} \quad$ Error ratio from the $500^{\circ} \mathrm{C}$ Isotherm Method 


\section{INTRODUCTION}

Precast prestressed hollow core (HC) slabs are widely used in concrete or composite floor structures in buildings. Because of their excellent structural performance at room temperature, advanced manufacturing methods, and low-cost installation, $\mathrm{HC}$ slabs have an important market presence in many countries. Prestressed reinforcement improves the serviceability performance of HC slabs compared to plain slabs (those without voids), increasing the cracking moment as well as the load-bearing capacity. Span lengths of up to 16 meters and high load levels can be achieved with HC slab floor systems. HC slabs must be installed in different ways depending on the support conditions and desired behavior of the floor structure. There are constructive arrangements compatible with in-situ concrete beams, precast concrete beams (I-sections, reversed T-sections), and steel beams, all of them with or without topping (i.e. upper concrete layer) [1] . It is therefore clear that HC slabs offer a remarkable variety of benefits and choices for designers.

Considerable efforts were made in order to evaluate the behavior of $\mathrm{HC}$ slabs at room temperature, and in most cases, an acceptable agreement between design provisions and test results was found $[2,8]$. However, some authors have pointed out the complexity of the thermomechanical behavior of HC slabs [9] which causes problems when fire resistance has to be assessed. When the slab heats up, phenomena such as thermal stresses and degradation of material properties should be taken into account as well as their interaction with the four known failure modes of HC slabs (bending, shear tension, shear compression, and anchorage) [2] . Moreover, temperature field is significantly affected by the moisture content of concrete and the presence of cavities (i.e. hollow cores) [9] . The simultaneous consideration of all the phenomena occurring in fire situations leads to a highly non-linear problem which usually requires the use of numerical methods for its resolution. In contrast, design standards such as EC2 [10] provide simplified methods in order to easily meet fire resistance requirements, but 
they give rise to uncertainties and unexpected failures. In the course of the last few years some authors have conducted fire tests to further knowledge of $\mathrm{HC}$ slab behavior at elevated temperatures although a significantly smaller amount of test data is available in comparison to that of room temperature. For instance, Cooke [11] carried out 14 tests but only two specimens were $\mathrm{HC}$ slabs while the other 12 were precast concrete floor slabs without voids or prestressed reinforcement. However, detailed information on temperatures and deflections was provided, enabling important observations to be made and applied to HC slabs.

Borgogno and Fontana [12] studied the behavior of slim floors in fire situations and developed a method for calculating thermal stresses. This method is applicable for both Bernouilli regions (where the Bernouilli hypothesis is fulfilled, i.e. mid-span zone) and nonBernouilli regions (i.e. support zone). Two series of tests were also carried out. The first series aimed to analyze failure modes and structural resistance at room temperature and showed a suitable correspondence with the known calculation methods. The second series was carried out to study the structural behavior of slim floor slabs at elevated temperatures, and suitable agreement was also obtained. Fellinger et al. [13] investigated shear and anchorage behavior of HC slabs exposed to fire. A total of 25 reduced scale tests was carried out and a numerical model was developed which took into account bond models for reinforcement steel-concrete interface. Double-rib specimens cut from entire slabs were used in most of those tests. It was concluded that shear and anchorage could lead to premature and unexpected failure. Bailey and Lennon [14] performed two large-scale fire tests on a hollowcore floor plate. They concluded that the small-scale standard fire tests, used to assess fire resistance periods, can be very unrealistic and ignores the beneficial effects of whole building behavior.

Finally, van Overbeek et al. [15] studied the premature partial collapse of HC slab floor structures following a real fire in a car park in Rotterdam. This study comprises the description of the damages observed as well as previous worldwide research of fire tests on HC slabs. A 
total of 121 tests were collected. Van Overbeek [15] imposed a series of criteria in order to discard tests in which important data were not recorded or those whose execution was dubious. It was found that only 32 tests out of 121 had full agreement of all criteria. This showed that reliable tests are scarce and mostly remain unpublished. In addition, it was found that premature failure occurred in $45 \%$ of the tests consulted, something which shows the need for further research.

Design codes such as EC2 [10] evaluate fire resistance using different methods such as the $500^{\circ} \mathrm{C}$ Isotherm Method (500IM) or the Tabulated Data Method (TDM), which are intended for calculating bending and fire resistance. The main parameter of these methods is average axis distance and its value determines fire resistance. This approach is usually assumed to be appropriate and able to predict fire resistance accurately. In consequence, research efforts have mainly concentrated on the assessment of shear capacity of HC slab units or HC slab floors at elevated temperatures. The interaction between shear tension and anchorage failures has also been outlined by many authors [12] [13] . However, flexural failure at elevated temperatures has been relatively neglected and few tests are available. Although the influence of the reinforcement arrangement at room temperature is clear when studying bending behavior, other aspects such as the effects of using wires or strands have not been analyzed at high temperatures.

Hence the objective of this paper is to develop an experimental program to expand the knowledge of bending behavior at elevated temperatures and to evaluate the influence of different reinforcement arrangements in the fire resistance rating (FRR). The authors have focused the study in standard scale fire tests despite of the beneficial effects stated by full-scale fire tests [14]. Furthermore design codes are mainly based on standard scale fire tests because the full-scale fire tests are more difficult and expensive to perform, neglecting therefore their beneficial effects. 
These results will be compared with the current verification methods given in EC2 in order to check their validity.

\section{EXPERIMENTAL PROGRAM}

\subsection{Tested specimens}

A total of four standard scale fire tests were performed within this experimental program. These slabs tend to be manufactured in very small batches and given the expense of producing a limited number of slabs expressly for the program the $\mathrm{HC}$ slabs chosen for testing were commercially available. In addition, manufacturers usually design the reinforcement arrangement with a view to satisfying a required bending moment at room temperature. Thus the four HC slabs selected had very similar flexural capacity at room temperature but different reinforcement arrangements and different fire resistance times predicted using simplified methods from EC2. Hereby the effect of the potential degree of prestressing induced on the slab via load or stress through the wires and strands is not representative.

Specimens tested were identified as follows: $\mathrm{HCxx}-\mathrm{Ay}$, where ' $\mathrm{xx}$ ' is the cross-section height and ' $y$ ' identifies the reinforcement arrangement. Slab identification is ordered from lowest to highest average axis distance (defined below in equation (1)), i.e. the average axis distance of HC25-A1 is less than that of HC25-A2.

Table 1 and Figure 1 characterize their geometry. All HC slabs were $250 \mathrm{~mm}$ high, 1200 $\mathrm{mm}$ wide, $5700 \mathrm{~mm}$ long, and only the reinforcement arrangement was varied. Two types of tendons were used: $5 \mathrm{~mm}$ diameter wires and 3/8" $(9.5 \mathrm{~mm})$ diameter strands. Reinforcement was distributed along the cross-section in five rows and most of the tendons were placed on the central web axis. Only 4 wires in row number 1 of specimen HC25-A1 were eccentrically placed $18 \mathrm{~mm}$ away from the central web axis, Figure 1a. 
As the influence of reinforcement arrangement in bending failure is investigated in this work, the most important parameter to be studied is the average axis distance. This will be calculated as follows in compliance with EC2:

$$
a_{m}=\frac{\sum_{i} A_{p i} \cdot f_{p i} \cdot a_{i}}{\sum_{i} A_{p i} \cdot f_{p i}}
$$

where:

$A_{p i}$ is the cross-sectional area of the tendon ' $\mathrm{i}$ '.

$f_{p i}$ is the real tensile strength of the tendon ' $\mathrm{i}$ ', which was obtained as explained in section 2.3.

$a_{i}$ is the axis distance of the tendon ' $\mathrm{i}$ ' from the nearest exposed surface.

Therefore, real strength of steel is used and only reinforcement under tension (rows 1 to 4) is considered in the calculation. Average axis distance of each HC slab is shown in Table 1.

\subsection{Concrete}

Normal-strength concrete (45 $\mathrm{MPa}$ ) and calcareous aggregates were used in the experimental program. The real compressive strength of concrete was determined by testing two cylinders, 300 and $150 \mathrm{~mm}$ long, on the same day the HC slab was tested. The cylinder compressive strength of concrete $f_{c}$ was calculated as the average of the two test results. Since flexural failure is expected, the real tensile strength of concrete $f_{c t}$ is also needed. A Brazilian test procedure [16] was performed using one cylindrical sample. All data are summarized in Table 2.

The humidity of concrete was also measured using cubic samples cut from each slab on the same day they were tested. The weight of each specimen was measured before and after 
drying them in a small oven at $150^{\circ} \mathrm{C}$. This made it possible to obtain the moisture level directly. Furthermore, all the hollow core slabs were tested with more than 3 months of drying, Table 2.

\subsection{Prestressing steel}

Cold-worked prestressing steel wires and strands were used. Strands were made up of six wires rolled together in a helical form around a central wire. The characteristic tensile strength of steel $f_{p k}$ was $1860 \mathrm{MPa}$ in all cases. However, real strength was established by experimental coupon tests. A tensile strength of $1931 \mathrm{MPa}$ was obtained for strands, while the tensile strength measured for wires was $1883 \mathrm{MPa}$. These values apply to all $\mathrm{HC}$ slabs tested as the steel used in all cases belonged to the same batch.

The $0.1 \%$ proof-stress of prestressing steel $f_{p, 0.1}$ was also obtained, given that it was of interest for the calculation of the real ultimate bending moment at room temperature. It was established that $f_{p, 0.1}$ was equal to $90 \%$ of real tensile strength of steel $f_{p}$ for both wire and strands. This result matched the recommendations of EC2, which suggest considering the same percentage $(90 \%)$ in absence of experimental data.

\subsection{Test setup and procedure}

All tests were performed in the testing facilities of AIDICO (Instituto Tecnológico de la Construcción) in Valencia, Spain. Both the experimental setup and test procedure were in compliance with standard EN 1363 [17] for fire resistance tests. A $5 \times 3$ m furnace equipped with a hydraulic jack of $1000 \mathrm{kN}$ maximum capacity was used. There were 16 gas burners inside the furnace chamber, arranged in two horizontal rows of 8 burners each, located at midheight on opposite walls. Slabs were placed covering the furnace, and only supported at the ends. Figure 2.a shows a general view of the experimental setup, while the interior of the furnace can be seen in Figure 2b. As bending behavior was of interest, a four-point test 
arrangement was used to apply the load. Figure 3 shows a setup scheme indicating the principal lengths. There was no interaction between shear and bending in the two load points, that is to say, pure bending occurs. Mid-span deflection was measured using a displacement transducer.

Furnace temperature was automatically controlled by five thermocouples (plate thermometer) following standard fire curve ISO-834 [18] . Pressure sensors were also located inside the furnace chamber in order to prevent excessive values. Temperatures inside each HC slab were measured with sixteen thermocouples distributed in two cross-sections (section A and section B) equidistant from the mid-span (Figure 4). Thermocouples were arranged in both sections according to the following criteria:

- Thermocouple No. 1 on the unexposed (top) surface.

- Thermocouple No. 3 at mid-height.

- Thermocouple No. 8 on the exposed (bottom) surface.

- Thermocouple No. 4 inside one void. It was noted that in the literature for numerical purposes the temperature inside the void is usually assumed to follow the average temperature of the void surface [19]. Placing a thermocouple inside one of the voids makes it possible to evaluate the accuracy of this assumption.

- The other four thermocouples (numbers 2, 5, 6, and 7) were placed at the same height as a reinforcement row, which provided an indirect reading of the reinforcement temperature. In the case of specimen HC25-A4 only three out of four thermocouples were installed because of the reinforcement arrangement.

In order to place the thermocouples inside the concrete it was necessary to drill holes to an appropriate length. Once the thermocouples were placed, the holes were filled with thermal insulation. Figure 4 shows an example of the thermocouple arrangement system used in Section A and Section B of slab HC25-A2 respectively, with thicker lines representing the drilled holes. Both arrangements can be seen to be symmetrical. For example, thermocouple number 6 in 
Section A is placed inside the second web while thermocouple number 6 of Section B is placed inside the ninth web. The second and ninth webs are symmetrical to the center of the section. This disposition makes it possible to perceive any difference in temperature and ensures uniform heating. Moreover, because of the border effects any thermocouple placed inside the outer webs (1 and 10) could distort the temperature measurement process. Finally, Figure 2c shows how the void ends of the HC slabs were filled with insulating material. The purpose of this was to prevent air renovation inside the void and reproduce building conditions in the test. Moreover, had air renovation been allowed, it would have been impossible to evaluate suitability as the temperature inside the void follows the average temperature of its surface, as stated above.

The load applied was identical for all slabs tested and was calculated aiming to obtain an average nominal load level of $45 \%$. The individual load level of each slab was calculated as follows:

$$
\mu_{\text {nom }}=\frac{M_{\text {Test }}}{M_{R d, n o m}}
$$

where $M_{\text {Test }}$ is the bending moment produced by the applied load and $M_{R d, n o m}$ is the ultimate bending moment at room temperature using the nominal properties for materials and the corresponding partial factors. Nominal properties were used as these calculations were made before the experimental data of materials were available. The average nominal load level was considered to be equal to $45 \%$ as this value leads to an average FRR of 90 minutes from the $500^{\circ} \mathrm{C}$ Isotherm Method, using nominal properties of materials and partial factors $\gamma_{M, f i}$ in a fire situation equal to one [10] . Moreover, temperatures were taken from the product standard for HC slabs EN 1168 [20], which provides a temperature profile throughout the section for each 
time of fire exposure. It should be noted that these temperature profiles are identical to those given in EC2, despite the fact that these are intended for solid slabs.

The bending moment in all tests $M_{\text {Test }}$ could be calculated $(52.6 \mathrm{~m} \cdot \mathrm{kN})$ from an average nominal load level of $45 \%$. The test load $P_{\text {Test }}$ could also be calculated immediately considering the loading system shown in Figure 3. Consequently, a test load of $58.80 \mathrm{kN}$ was obtained and applied in all tests.

In contrast, the experimental (i.e. real) load level of the slabs tested is another important parameter. When real material properties are known, the experimental load level can be calculated as follows:

$$
\mu_{\text {exp }}=\frac{M_{T e s t}}{M_{R d, \exp }}
$$

where $M_{R d \text {,exp }}$ is the ultimate bending moment at room temperature, calculated by means of the experimentally measured properties of materials. Therefore, partial factors for materials were not needed in this case. Table 2 summarizes $\mu_{\exp }$ values of each slab. As was stated in section 2.1, the ultimate bending moments at room temperature were almost equal for all slabs, and therefore, the experimental load levels are very similar.

\section{TEST RESULTS}

\subsection{Test observations}

During the first 25 minutes of fire exposure, spalling was perceived in all tests thanks to its characteristic noise. Table 3 summarizes the number of cases of spalling as well as their time of occurrence. Furthermore, Figure 5 shows two pictures where two holes produced by spalling on the bottom surface of unit HC25-A2 could be identified after testing. In all tests it 
was observed that spalling was more likely to appear near the supports, although in some cases it also appeared in the central zone.

Four types of cracking were identified in tested slabs: thermal cracking, flexural cracking, splitting, and longitudinal cracking. All these are shown in Figure 6 while Figure 7 gives a general view of the $\mathrm{HC}$ slabs after testing.

\subsubsection{Thermal cracking}

Thermal cracking, produced by tensile stresses due to the non-linear temperature profiles throughout the section, occurred in the webs of the slabs [12] . This thermal cracking was perfectly vertical and appeared to be uniform between the two load points, i.e. all the cracks were almost the same length and equally spaced inside this zone. These cracks gradually became shorter the closer they got to the supports, until they eventually disappeared. Tensile stresses due to the bending moment interacted with tensile thermal stresses, and thus major cracking was caused in the central zone of the slab.

\subsubsection{Flexural cracking}

As material properties suffered greater damage, deflection increased and the thermal cracking turned into flexural cracking as it developed through the bottom flange. This type of cracking was observed between the two load points where the applied bending moment reached its maximum value.

\subsubsection{Splitting}

A partial loss of contact between reinforcement and concrete took place due to the high temperature gradient at the lower part of the section and the different thermal conductances of steel and concrete [19]. The temperature in the tendon cross-section was uniform thanks to the high thermal conductivity of steel, and it therefore showed an axially symmetrical expansion. 
However, the concrete cover at the bottom side of the tendon expanded more than the concrete cover at the top side because of the high temperature gradient, causing the concrete perimeter around the tendon to change from a cylindrical to an ellipsoidal shape. Obviously, this became more pronounced the greater the tendon diameter. The opposite behavior was observed when using $5 \mathrm{~mm}$ diameter wires and 3/8" diameter strands $(9.5 \mathrm{~mm})$, because splitting cracks occurred around some strands in the border section (see Figure 6d) but not around the wires. In addition, high temperatures led to degradation of bond properties, so the anchorage capacity was reduced and a certain sliding of the strands was observed in the border section of the slab. As strands penetrated the concrete, they produced local stresses around the reinforcement which led to splitting cracks.

Horizontal splitting cracks, described by Fellinger [19], were not observed in the tests presented in this work as the lateral cover of the strands was great enough.

\subsubsection{Longitudinal cracking}

Finally, longitudinal cracking developed in all tested slabs. This type of cracking has been explained by Fellinger [19] as the result of a transverse bending moment caused by thermal expansion. Due to the lack of reinforcement in the transverse direction, this bending moment caused longitudinal cracking in the weakest cross-section, where the flange thickness had its minimum value. As a result, the $\mathrm{HC}$ unit was split into individual ribs. Figure 8 shows the crosssection crack pattern and distinguishes the slabs with wire reinforcement which showed no splitting cracks, and the slabs with wire/strand reinforcement which showed splitting around the strands.

In addition, during testing there was a major release of steam from the voids of the slab, although the void ends were filled with insulating material. This is explained by the porous nature of the insulation. Furthermore, it appeared that moisture tended to flow around the 
strands affected by splitting cracks. On arrival at the end section, this flow of moisture condensed into water. Some authors have suggested that this phenomenon could distort the temperature field around the reinforcement [19]. If this were the case, the correct temperature of the strands could not be deduced if thermocouples were placed at the same height, since the thermocouples would have to be in contact with the strand. Assuming this hypothesis implies that heating of strands would be delayed thanks to the moisture vaporization. However, as the tendon temperature was not measured directly, it was not possible to prove or refute this hypothesis.

\subsection{Mid-span deflection and failure mechanism}

When HC slabs showed a flexural failure at elevated temperatures, three different stages were identified in the deflection versus time curve. These stages are noted in Figure 9.

In the first stage, which comprised the first 20 minutes of the fire testing approximately, heating from below gave rise to a non-linear temperature profile through the cross-section which led to the development of tensile thermal stresses in the web, while the top and bottom flanges were in compression [12]. The tensile thermal stresses led to the web cracking and therefore the deflection increased rapidly at this stage. In contrast, the steel reinforcement was barely affected by the temperature for the first 20 minutes, so this pronounced loss of stiffness cannot be attributed to its loss of strength. However, without a proper temperature measurement on the tendon it is very difficult to make a reliable statement neglecting totally the effect of the degradation of steel.

After 20 minutes, the second stage began. There was an almost linear increase in midspan deflection. The webs were completely cracked and the temperature profiles through the section became smoother, so the loss of stiffness slowed down. The moisture vaporization at $100^{\circ} \mathrm{C}$ also contributed to delaying the rise in temperature. During this stage, the deflection 
mainly took place because of the degradation of material properties. Therefore, as the rise in temperature slowed down, the materials slowly lost their mechanical properties and the deflection rate was moderated. The second stage concluded when the steel reinforcement lost its strength and the deflection rate increased quickly, so that the timespan of this stage was variable and depended on the reinforcement arrangement of each slab.

During the third stage, the HC slab fully lost its load-bearing capacity. A high deflection rate was observed up until the test was finished (see Figure 9). Before the test began, the reinforcement steel operated in the elastic range since the real load level was low (about 36\%). As the slab heated up, the elastic modulus of the steel decreased, and therefore the deflection rose. The applied load was maintained during the test so the stress level did not change in order to maintain overall equilibrium. At a given temperature yielding stress and current stress became equal, which meant that the steel showed plastic strain.

As the steel yielded and the temperature kept rising, the steel continued to lose strength and therefore some tensile force was transferred to the rows of reinforcement above (when possible). Depending on the area of reinforcement of the rows above and their lever arm, the increment of stress produced by the tensile force released was of greater or lesser significance. When the steel area of the bottom row was much greater than the area of the other rows, the tensile force released produced a great increment of steel stress in the rows above. This increment could immediately lead to the steel in the row yielding. This process continues until all steel rows have yielded or the concrete in compression has been crushed.

Figure 10 shows the mid-span deflection measured during the test for each slab. Although all four curves are similar, some differences can be noticed in the third stage of each HC slab. While the deflection rate of HC25-A1 increases very rapidly in the final stage, that of HC25-A3 is considerably lower. This behavior is explained by the failure mechanism described earlier. 
Finally, the three stages distinguished in the time-deflection curve of the HC slabs and which show flexural failure can be observed in the plain slabs (i.e. without voids) when experiencing the same type of failure. Results from Cooke [11] support this observation.

\subsection{Fire resistance rating}

According to EN 1363 [17], failure is considered to occur when the deflection limit or the deflection rate limit, are reached. These are calculated as follows:

$$
\begin{aligned}
& D=\frac{L^{2}}{400 \cdot d}(\mathrm{~mm}) \\
& \frac{d D}{d t}=\frac{L^{2}}{9000 \cdot d}(\mathrm{~mm} / \mathrm{min})
\end{aligned}
$$

where $\mathrm{L}$ is the distance between supports and $\mathrm{d}$ is the distance between the extreme zone in compression and the extreme zone in tension in bending at room temperature, both expressed in millimeters. Accordingly, Table 2 shows the fire resistance rating (FRR) of each slab tested within this experimental program. Table 2 also shows the maximum deflection reached for each slab and the maximum deflection rate, indicating the exceeded limits. Slab HC25-A4 appeared to be very damaged so the decision was made to halt the test, thus preventing the slab from falling inside the furnace. In the case of slab HC25-A2, which was tested first, the hydraulic jack reached its maximum displacement, so that the test had to be stopped. This problem was solved and all subsequent tests were carried out without further incidents. Even so, both HC25A2 and HC25-A4 had also reached at least one of the limits when their respective tests concluded (see Table 2).

FRR time measurements ranged from 84 to 105 minutes. This means that all four slabs failed within a timespan of 21 minutes despite the different reinforcement arrangements. Results from Table 2 also show that greater average axis distances led to greater FRRs, except 
in the case of unit HC25-A4 which displayed the second shortest FRR despite having the greatest average axis distance.

\subsection{Temperatures}

The temperatures measured were expected to be similar for all the slabs as the concrete section was the same and the influence of the reinforcement could be neglected [10]. Only the moisture content was expected to produce differences in the temperatures measured, because the exposure to the standard fire curve was practically perfect, as shown in Figure 11. The standard fire curve ISO 834 is represented by a gray dotted line, while the temperature measured inside the furnace is represented by a black line. Both curves are almost identical, so it is clear that the control system of the furnace temperature worked very well in this test. Although the curves of the other tests are not shown for the sake of simplicity, the temperature was an almost perfect match for the ISO 834 curve in all tests.

Figure 12 compares the time-temperature curves recorded by thermocouple number 3 , located at mid-height, for each slab tested with the purpose of evaluating the influence of moisture. For this reason the moisture content has been indicated beside each curve. As expected, greater moisture content leads to an extended plateau at $100^{\circ} \mathrm{C}$. In addition, the timespan of these plateaus corresponds to the experimentally measured moisture, that is to say similar moisture contents lead to similar plateau timespans. As stated before, curves for all slabs are almost identical and differences are due to the moisture content for each slab.

However, the analysis of test results shows that a measuring error might have been induced when thermocouples were drilled from below. Figure 13 shows thermocouple number 6 (at $39.5 \mathrm{~mm}$ from the exposed face) in Section A of each slab, where two groups of curves can be identified. The first group corresponds to slabs drilled from above (DfA), while those drilled from below (DfB) show a time-temperature curve almost parallel but about $100^{\circ} \mathrm{C}$ 
higher. Furthermore, moisture vaporization is apparent when drilling from above, but not when drilling from below. These different measurements have been observed in spite of the fact that the holes drilled for placing thermocouples were filled with thermal insulation. Thus, it appears that thermocouples placed by drilling the bottom surface provide overrated measurement readings, which means that a different positioning system for thermocouples should be designed for future research. Placing all thermocouples from above might solve this problem but it would be necessary to get round the reinforcement in order to reach the lower rows.

Only reliable temperatures should be used in order to obtain consistent results, but some temperature readings were observed to be erroneous, pointing out possible inaccuracies in the calculations of the $500^{\circ} \mathrm{C}$ Isotherm Method (see section 4.2). It is therefore necessary to find a new method for obtaining reliable temperatures. A numerical model for simulating thermal behavior of $\mathrm{HC}$ slabs is needed to make this possible. This model must be validated through the result comparison with temperatures corresponding to thermocouples drilled from above, as these are unquestionable. Consequently, only thermocouples 1 to 6 will be used in the comparison. If the numerical model is adequately validated as a result of the comparison, then it will be possible:

- To compare temperature profiles provided in EC2 [10] and EN 1168 [20] , intended for solid slabs, with the results from the numerical analysis which includes the influence of the voids in the heat transfer.

- To predict temperatures at points where these were not measured.

- To predict temperatures beyond the time at which the test concluded.

- To discard incorrect measurement readings through the comparison with numerical results.

The advantages provided by the numerical model are therefore highly valuable. 


\subsubsection{Brief description of the numerical model and results}

The numerical model was developed using the commercial software ABAQUS, and was part of a three-dimensional thermo-mechanical model for predicting the behavior and crack patterns of HC slabs at elevated temperatures. The finite element method was used and thermal properties stated in EC2 were applied. The reinforcement was not modeled because, in principle, it can be assumed that its influence on the temperature field is negligible [10] . Radiation and convection inside the voids were also taken into account, and it was assumed that the air temperature inside the voids was equal to the average temperatures of the void surfaces.

As a result of the numerical model, the temperature field throughout the $\mathrm{HC}$ slab is obtained for each time of exposure. Each graph in Figure 14 comprises the two measures from the thermocouples placed at a given height in Section A and Section B as well as the numerical results at the same point. The temperatures calculated with the numerical model are represented by a dotted line. As can be observed, suitable agreement was obtained, leading to the conclusion that the numerical model is capable of reproducing the temperature field of the HC slabs exposed to fire. In Figure 14, only the comparison with unit HC25-A2 is carried out, and results from the other slabs are not shown for the sake of simplicity. Moreover, the time-temperature curves recorded for each slab are similar due to the narrow range of variation of the moisture (from $2.9 \%$ to $3.9 \%$ ). In fact, differences remain below $100^{\circ} \mathrm{C}$, making the information presented in Figure 14 sufficiently representative.

As stated in section 2.4, two thermocouples were placed at the same height from the bottom surface and symmetrical to the center of the cross-section. By doing so, it was possible to evaluate whether heating was uniform. No relevant difference was found, with the exception of Figure 14, where considerable differences were observed between the two thermocouples. Thanks to the numerical model, the discrepant measurement can be identified and ruled out. Despite this isolated case, it can be concluded that exposure was appropriate. 
The effect of moisture in the time-temperature curve is clearly illustrated in Figure 14c using thermocouple number 3, located at mid-height. About 40 minutes (2400 seconds) after the start of the test, the temperature at this point reaches $100^{\circ} \mathrm{C}$ and is maintained at the same value for nearly 45 minutes (up to 5100 seconds) thanks to moisture vaporization. In addition, it has been noted that time-temperature curves had different shapes depending on the height the temperatures were measured at. The lower the thermocouple, the quicker it heated up, so that the effect of moisture vaporization became almost imperceptible. Moisture effect was very noticeable in Figure 14c for instance, while it barely appeared in Figure 14f.

On the other hand, thermocouple number 4, located at mid-height inside one void, showed some disturbance explained by the convective air flow enhanced by the different temperatures of the void surfaces (see Figure 14d). Other authors affirm that this disturbance is because the moisture from evaporation may play an important role. The average temperature of the void surfaces calculated with the numerical model has also been included in this figure. As can be seen, a good prediction was obtained, so it is logical to assume that the air temperature inside the void is equal to the average temperature of the void surfaces.

\section{VERIFICATION OF SIMPLIFIED METHODS}

In this section, the FRR measured in tests is compared with the FRR predicted from the two simplified methods given in Eurocode 2 [10] in order to evaluate their validity, although the limited number of tests does not make it possible to establish solid conclusions.

\subsection{Tabulated Data Method}

The Tabulated Data Method (TDM) makes it possible to obtain the fire resistance rating directly from the average axis distance by comparing with the tabulated data. Depending on the type of element under study (beam, slab, etc.), EC2 provides a different table where the average axis distance required for achieving a certain FRR is established. Although EC2 only 
considers solid slabs (i.e. not HC slabs), the product standard for hollow core slabs EN 1168 [20] gives the average axis distance required in order to achieve a specific resistance time. Furthermore, the average axis distances given by EC2 in case of simply supported solid slabs fully agreed with those provided by EN 1168, which means HC slabs can be treated in the same way as solid slabs.

The first step in the TDM is the calculation of the average axis distance of each slab as explained in section 2.1. Only tendons lying in rows 1 to 4 were taken into account and the real strength of steel was applied (1931 MPa for strands and $1883 \mathrm{MPa}$ for wires).The values of average axis distance given in the corresponding table for simply supported solid slabs were increased considering the following expression:

$$
\Delta a=0.1 \cdot\left(500-\theta_{c r}\right)
$$

where $\theta_{c r}$ is the critical temperature, which can be obtained from a graph found in EC2, clause 5.6. This graph depends mainly on the load level and the type of reinforcement. For instance, a load level of $70 \%$ leads to a critical temperature of $350^{\circ} \mathrm{C}$ if prestressing wires and strands are used. When using the expression given above a critical temperature of $350^{\circ} \mathrm{C}$ means that an increment of $15 \mathrm{~mm}$ must be applied to the tabulated data. As experimental load levels of the tested slabs were much lower (see Table 2) a new critical temperature was obtained for each slab. In addition, calcareous aggregates were used for concrete in all cases, so the tabulated data may be reduced by $10 \%$ following the recommendations of EC2.

Taking into consideration all the rules presented previously, the procedure defined in EC2 was followed and the relevant corrections of average axis distance were calculated for each slab. Table 4 summarizes the results obtained using the Tabulated Data Method and the corrections of the average axis distance are denoted by $\Delta a$. Figure 15 shows an FRR comparison from the Tabulated Data Method and features the FRRs measured in tests. All 
results from the TDM appear to be unsafe and moreover, it can be noted that the discrepancies increase the greater the FRR predicted. In order to evaluate the discrepancy of the TDM for each test, the error ratio $\varepsilon_{T D M}$ is calculated as follows:

$$
\varepsilon_{T D M}=\frac{F R R}{F R R_{T D M}}
$$

Obviously, if the error ratio is less than 1, the TDM result is unsafe, but if the opposite occurs and the error ratio is equal or greater than 1 then the TDM calculations are safe. Slab HC25-A1, reinforced only with wires, showed the best results with an error ratio of 0.98 .

\section{2 $500^{\circ} \mathrm{C}$ Isotherm Method}

Depending on the number of sides exposed to fire, Annex A for EC2 gives a series of graphs specifying the position of isotherms inside the cross-section for specific times of exposure to the standard fire curve. Using these graphs, the $500^{\circ} \mathrm{C}$ Isotherm Method reduces the cross-section by excluding any concrete over $500^{\circ} \mathrm{C}$, while the concrete below $500^{\circ} \mathrm{C}$ preserves its mechanical properties at room temperature. Reinforcements take their temperatures from the same graphs described before, as the properties of steel are reduced according to the individual temperature of each wire or strand. Even if reinforcement lies outside the reduced section, it must be considered in calculations, which means that it is assumed that sufficient anchorage capacity remains. The ultimate bending moment for a specific time of exposure is obtained using conventional calculation methods and considering the reduced cross-section with concrete properties at room temperature and steel properties reduced according to the temperature.

In the case of slabs with only the bottom surface exposed, isotherms are almost horizontal since a practically one-dimensional heat transfer process takes place. Therefore, EC2 gives temperature profiles throughout the slab section instead of isotherms inside the section. 
Although these temperature profiles are intended for solid slabs, product standard EN 1168 [20] also allows their application for HC slabs. As only the bottom side of the slab is exposed to fire, the concrete compression block is rarely affected by temperature and therefore the cross-section reduction does not affect the ultimate bending moment calculation.

The real properties of materials are applied since the validity of the $500^{\circ} \mathrm{C}$ Isotherm Method is being studied. Both, the temperatures obtained from standard EN 1168 [20] and the temperatures predicted by the finite element model were used, comparing both results in Table 4. The latter temperatures have been adequately validated, and can be observed in section 3.4.

Consequently, the ultimate bending moments can be calculated as explained earlier for each fire exposure time. The fire resistance rating (FRR) of each slab is obtained following the scheme shown in Figure 16, by intersecting the curve of ultimate bending moments (which decreases as time progresses) with the bending moment produced by the test load (which is constant throughout the test). Table 4 shows the FRR of each slab obtained as explained before. The full application of EC2 method (including both temperature and mechanical predictions) can be compared in this Table with the partial application of EC2 method (temperatures from the FEM model and mechanical predictions from EC2), showing similar predictions except for the last test.

Furthermore, Figure 17 shows a comparison of the FRR predicted using the $500^{\circ} \mathrm{C}$ Isotherm Method with the FRR measured in tests. The error ratio is defined as follows:

$$
\varepsilon_{500 I M}=\frac{F R R}{F R R_{500 I M}}
$$

Two out of four slabs (HC25-A1, HC25-A2) showed good agreement between predicted and measured FRRs. The $500^{\circ} \mathrm{C}$ Isotherm Method prediction is safe for units HC25-A1 and HC25-A2 and slightly unsafe for HC25-A3, while a notable deviation is observed for unit HC25-A4. Figure 18 compares the error ratio obtained using the Tabulated Data Method and 
the error ratio obtained using the $500^{\circ} \mathrm{C}$ Isotherm Method. Both error ratios are plotted versus the average axis distance, as the FRRs obtained from simplified methods depend mainly on this parameter. Safer results were obtained with the $500^{\circ} \mathrm{C}$ Isotherm Method, but both methods greatly overestimated the FRR of slab HC25-A4, with a deviation of almost $40 \%$.

Moreover, both methods tend to provide more unsafe results the greater the distance of the average axis, that is to say, the more major deviations are observed the greater the predicted FRR. To a certain extent, the FRR that can be achieved by increasing the average axis distance appears to be limited (see Figure 15 and Figure 17).

Therefore, it is confirmed that the first three slabs agreed with the $500^{\circ} \mathrm{C}$ Isotherm Method prediction with an acceptable scatter, while the premature failure of slab HC25-A4 requires further investigation.

Test parameters show that the experimental load level of slab HC25-A4 (37\%) is slightly greater than those corresponding to the other slabs (35-36\%). Despite the non-linear relation between load level and FRR, the variation of load level is barely appreciable so a different explanation is needed. Temperatures predicted by the numerical model did not explain the excessive FRR obtained using the $500^{\circ} \mathrm{C}$ Isotherm Method, since the numerical results were checked for each slab. Therefore, there is no evidence to support a definitive explanation for the premature failure of slab $\mathrm{HC} 25-\mathrm{A} 4$, but it is possible to present some hypotheses.

In the case of the longitudinal cracking, as explained above, this led to the HC slab splitting into individual ribs, causing the loss of transverse stiffness. However, simplified calculation methods see the HC slab as a one-way element, rather like a beam, and therefore longitudinal cracking should not be a determinant factor in mechanical resistance. Longitudinal cracking may be thought to have affected the temperature field, which would mean that all slabs should have displayed premature failure since they all showed longitudinal cracking. 
After ruling out the longitudinal cracking, the splitting observed around strands was considered. This could suggest a possible anchorage weakening. If bond properties degrade more rapidly than steel strength, strands cannot yield and other tendons would need to assume greater stress in order to maintain overall balance. This means that a bending-anchorage interaction could lead to failure. In addition, the $500^{\circ} \mathrm{C}$ Isotherm Method even allows the consideration of reinforcements lying outside the reduced cross-section, which means that anchorage is not taken into account. This fact might explain why the FRR is overestimated. However, this explanation does not apply to the other slabs with strand reinforcements (HC25A2 and $\mathrm{HC} 25-\mathrm{A} 3)$, which behaved in reasonable agreement with $500^{\circ} \mathrm{C}$ Isotherm Method predictions.

After this, the influence of spalling was considered. Table 3 shows that spalling occurred repeatedly in unit $\mathrm{HC} 25-\mathrm{A} 4$, even though the moisture content was not the highest. This fact might bear some relation to the reinforcement arrangement, as there was no reinforcement for almost the first $40 \mathrm{~mm}$ from the bottom of the slab. This lack of steel might have brought about more severe spalling, i.e., deeper holes which could have accelerated the temperature rise of the reinforcement.

For this reason, further research is needed in order to determine whether structural issues are to blame for the premature failure of unit HC25-A4. Further tests are needed to reproduce the premature failure of the slabs designed to resist prolonged periods of exposure to fire.

\subsection{Repetition of Test 4: HC25-A4-rep}

In order to guarantee the results and conclusions achieved in the previous section, the authors decided to repeat the test number 4 (HC25-A4-rep). The test was repeated almost one year later of the first test due to unavailability of the furnace. The data and results are listed in 
Table 2, Table 3 and Table 4, where a FRR of 96 minutes was obtained very similar to the 92 minutes of the original one, demonstrating the reliability of the results.

\section{CONCLUSIONS}

From the test observations and the discussion of results presented above, the following conclusions can be drawn:

- When fire bending tests were carried out four types of cracking occurred in HC slabs: thermal cracking, flexural cracking, splitting cracks, and longitudinal cracking.

- Three stages are identified in the time versus mid-span deflection curve when flexural failure occurs. In the first stage deflection is driven by thermal cracking, while in the third stage the slab suffers failure due to the loss of strength of the steel.

- The consideration of air temperature inside the void as following the average temperature of the void surfaces has been validated.

- Wire reinforcement showed optimal behavior. Wires did not suffer splitting, and moreover, unit HC25-A1, which only had wire reinforcement, exhibited the best error ratio. However, a more extensive experimental program is needed to support this observation.

- The reinforcement arrangement determines the shape of the time-deflection curve in the third stage.

- As expected, longer fire resistance times are obtained with greater values of average axis distance (with the exception of unit HC25-A4). However, the FRR improvement when increasing the average axis distance is not as significant as predicted with the simplified calculation methods. Moreover, it seems that the error resulting from the simplified methods becomes greater for high predicted FRRs, but 
this statement should be qualified with further research. While design strategies for achieving HC slabs with high fire resistance are commonly based on placing the reinforcement as far as possible from the exposed surface, this strategy may not be as effective as supposed.

\section{ACKNOWLEDGEMENTS}

The authors wish to express their sincere gratitude to the Generalitat Valenciana for help provided through project FIRE-STRUCT 1.

\section{REFERENCES}

[1] G. Capuano, B. Della Bella, P. Ghittoni, P. Morandi, S. Pereswiet-Soltan,Il solaio alveolare Progettazione e Impieghi, second ed., Associazione Produttori di Solai Alveolari Precompressi (ASSAP), Verona (Italia), 1999. (In Italian)

[2] J.C. Walraven, W.P.M. Mercx, The bearing capacity of prestressed hollowcore slabs, Heron. 28(1983)1-46.

[3] R.J. Becker, D.R. Buettner, Shear tests of extruded hollow core slabs, PCI Journal. $30(1985) 40-54$

[4] M. Pajari, H. Koukkari, Shear resistance of PHC slabs supported on beams. I: Tests, Journal of Structural Engineering.9(1998) 1050-1061.

[5] J. Hegger, T. Roggendorf, N. Kerkeni, Shear capacity of prestressed hollow core slabs in slim floor constructions, Engineering Structures. 31(2009) 551-559.

[6] A. Pisanty, The shear strength of extruded hollow-core slabs, Materials and Structures. 25(1992) 224-230.

[7] D. Lam, K.S. Elliott, D.A. Nethercot, Parametric study on composite steel beams with precast concrete hollow core floor slabs, Journal of Constructional Steel Research. 54(2000) 283-304. 
[8] J.Y. Song, K.S. Elliott, H. Lee, H.G. Kwak, Load distribution factors for hollow core slabs with in-situ reinforced concrete joints, International Journal of Concrete Structures and Materials. 1(2009) 63-69

[9] J.C. Dotreppe, J.M. Franssen, Precast hollow core slabs in fire: numerical simulations and experimental tests, Proceedings of the $3^{\text {rd }}$ International Workshop Structures in Fire.5(2004) 219-232.

[10] CEN. EN 1992-1-2, Eurocode 2: Design of concrete structures. Part 1-2: General rules Structural fire design. Brussels, Belgium: Comité Européen de Normalisation; 2004.

[11] G.M.E. Cooke, Behaviour of precast concrete floor slabs exposed to standardized fires, Fire Safety Journal. 36(2001) 459-475.

[12] W. Borgogno, M. Fontana, Structural behaviour of slim floor slabs with prestressed hollow core elements at room temperature and in fire, Proceedings of the Composite Construction in Steel and Concrete IV Conference.4 (2000) 768-79.

[13] J. Fellinger, J. Stark, J. Walraven, Shear and anchorage behaviour of fire exposed hollow core slabs, Heron. 50(2005) 279-301.

[14] Bailey CG, Lennon T, Full-scale fire tests on hollow core floors, The Structural Engineer 2008; 86: 33-39.

[15] T. van Overbeek, A. Breunese, J. Gijsbers, K. Both, J. Maljaars, L. Noordijk, New regulations for hollow core slabs after premature partial collapse. $6^{\text {th }}$ International Conference on Structures in Fire. 2010: 141-148.

[16] CEN. EN 12390-6, Testing hardened concrete. Part 6: Tensile splitting strength of test specimens. Brussels, Belgium: Comité Européen de Normalisation; 2009.

[17] CEN. EN 1363-1, Fire resistance tests. Part 1: General requirements. Brussels, Belgium: Comité Européen de Normalisation; 1999. 
[18] ISO 834: Fire resistance tests, elements of building construction. Switzerland: International Standards Organization; 1980.

[19] J. Fellinger, Shear and anchorage behaviour of fire exposed hollow core slabs, $\mathrm{PhD}$ dissertation, Delft, The Netherlands, 2004.

[20] CEN. EN 1168, Precast concrete products. Hollow core slabs. Brussels, Belgium: Comité Européen de Normalisation; 2006. 


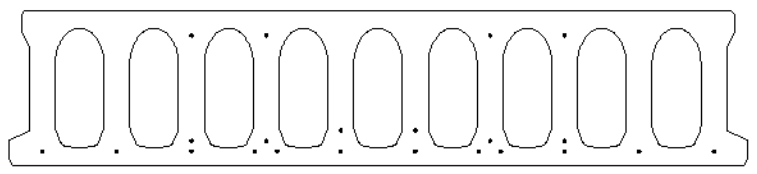

a) $\mathrm{HC} 25-\mathrm{A} 1$

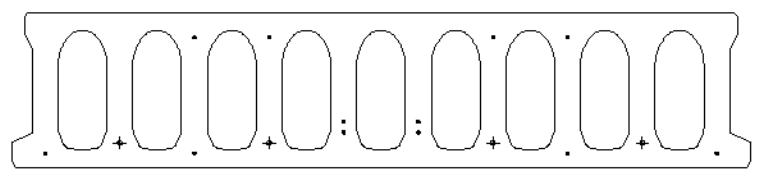

c) $\mathrm{HC} 25-\mathrm{A} 3$

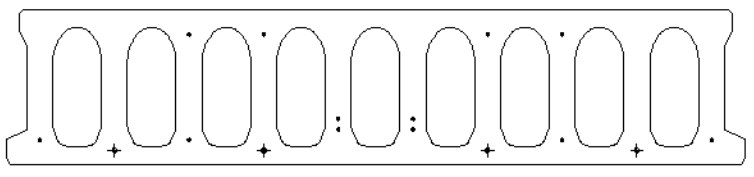

b) $\mathrm{HC} 25-\mathrm{A} 2$

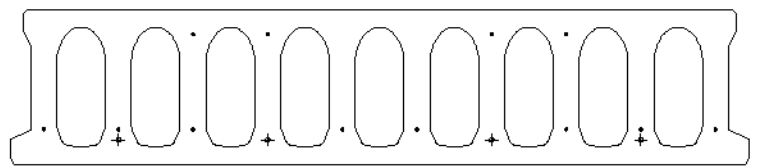

d) $\mathrm{HC} 25-\mathrm{A} 4$

\section{Strand - Wire}

Figure 1. Cross-section and reinforcement arrangement of the HC slabs tested 
Aguado JV, Espinos A, Hospitaler A, Ortega J, Romero ML. Influence of reinforcement arrangement in flexural fire behavior of hollow core slabs. Fire Saf J. 2012;53:72-84. doi: 10.1016/j.firesaf.2012.06.015
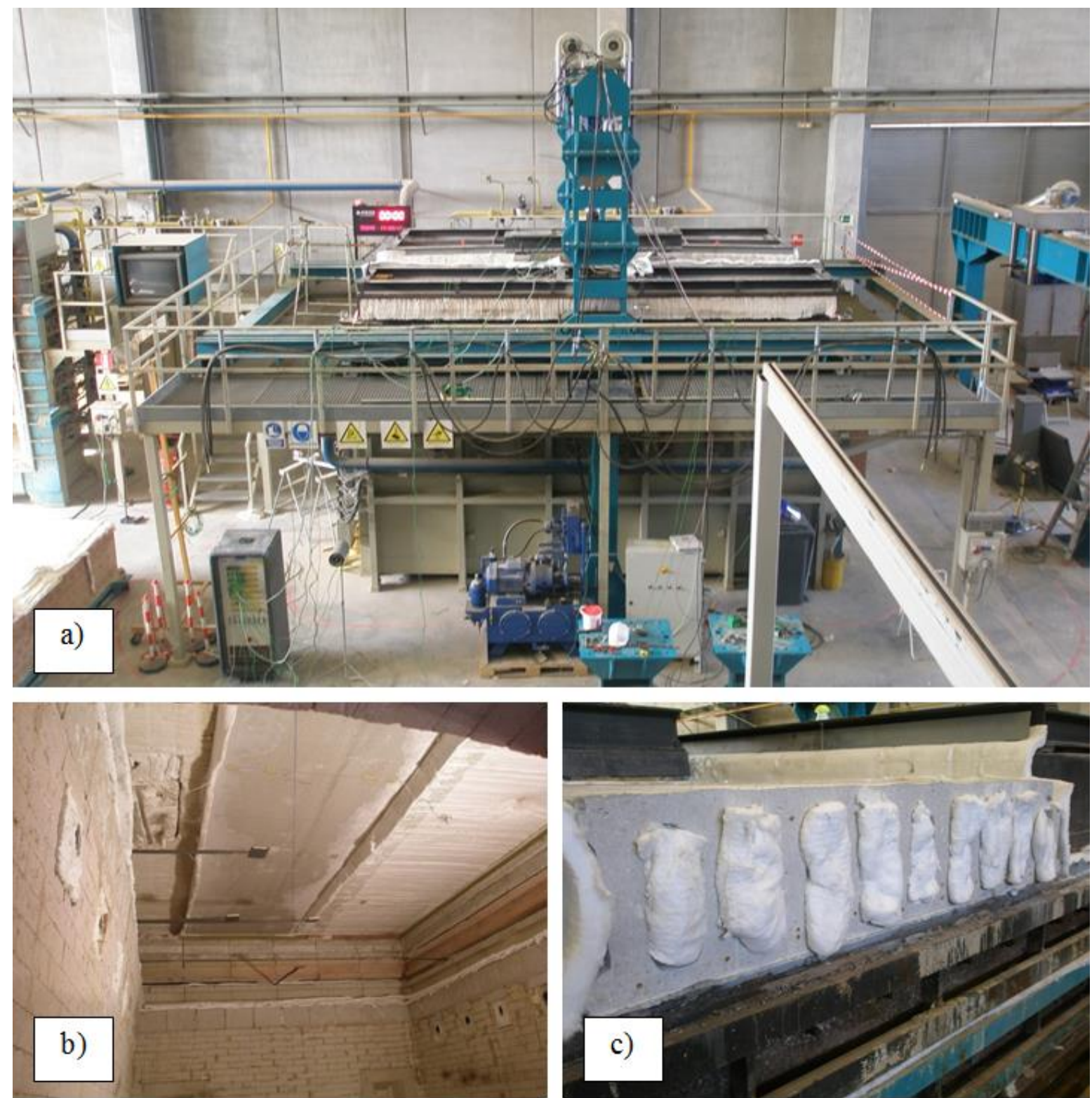

Figure 2. a) General view of the experimental setup. b) Inside the furnace. c) HC infilling 
Aguado JV, Espinos A, Hospitaler A, Ortega J, Romero ML. Influence of reinforcement arrangement in flexural fire behavior of hollow core slabs. Fire Saf J. 2012;53:72-84. doi: 10.1016/j.firesaf.2012.06.015

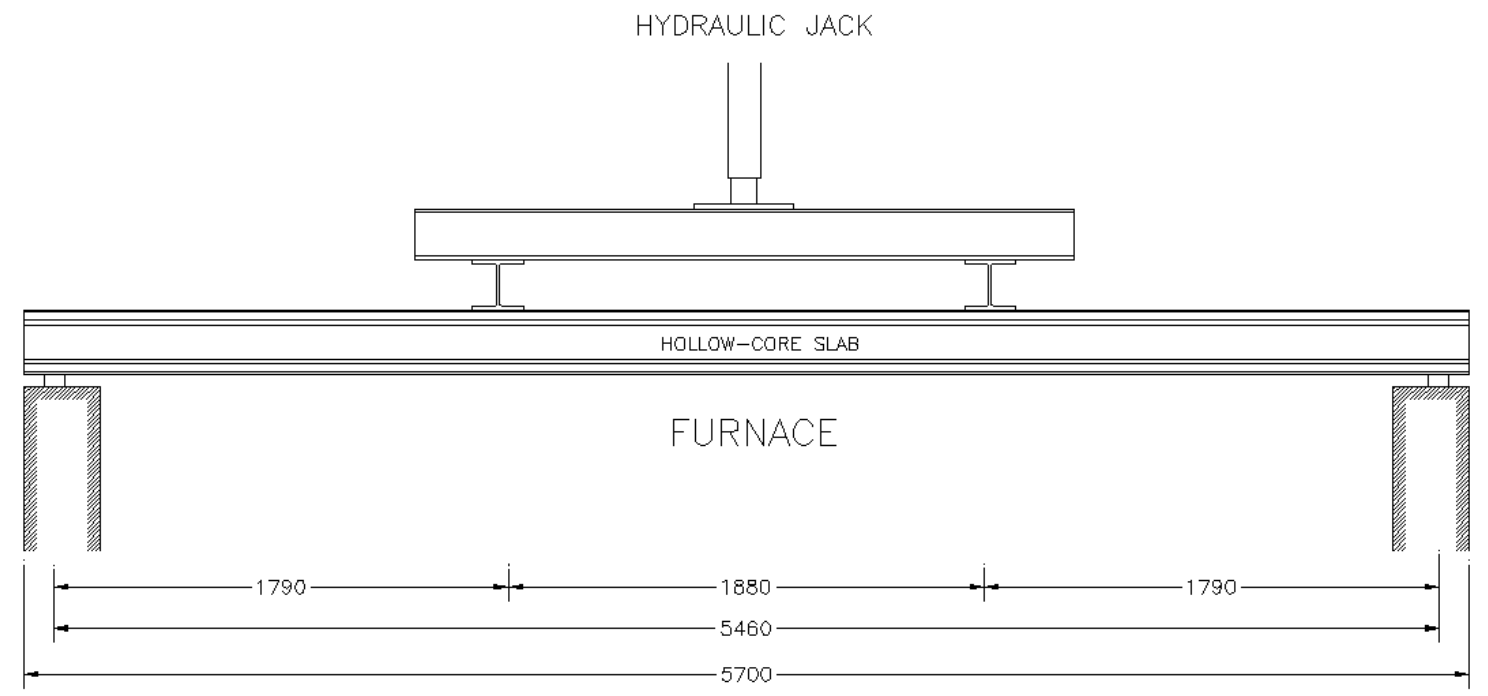

Figure 3. Representation of the experimental setup. 


\section{SECTION A}

$\begin{array}{lllll:lllll}4 & 2 & 3 & 4 & 5 & 9 & 7 & 9 & 9 & 9\end{array}$

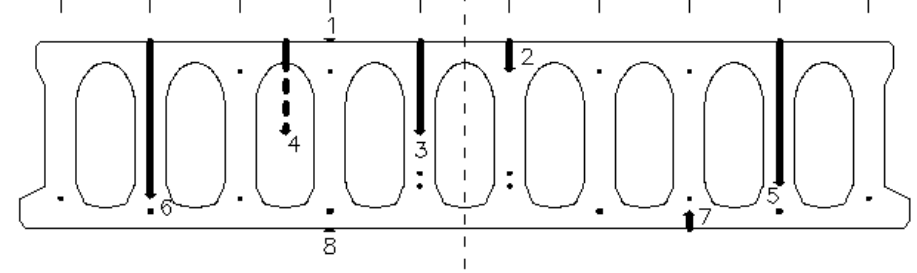

SECTION B

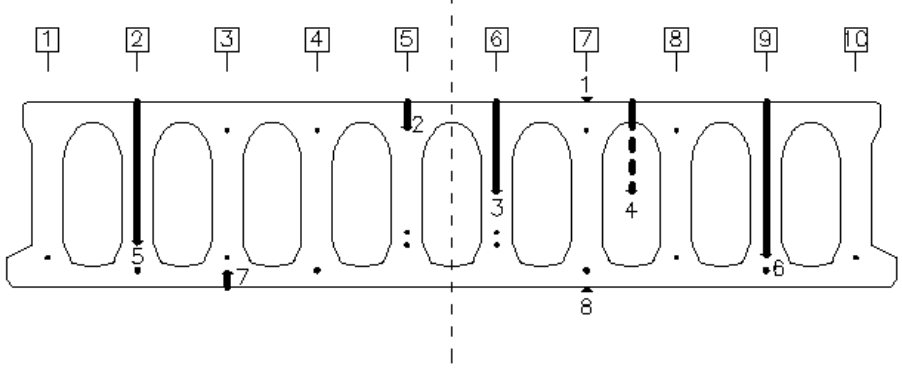

\begin{tabular}{|c|c|c|}
\hline $\begin{array}{c}\text { Thermocouple } \\
\text { No. }\end{array}$ & $\begin{array}{c}\text { Height } \\
\text { (mm) }\end{array}$ & $\begin{array}{c}\text { Reinforcement } \\
\text { Row }\end{array}$ \\
\hline 1 & 250 & - \\
\hline 2 & 210.5 & 5 \\
\hline 3 & 125 & - \\
\hline 4 & 125 & - \\
\hline 5 & 60 & 3 \\
\hline 6 & 39.5 & 2 \\
\hline 7 & 22.5 & 1 \\
\hline 8 & 0 & - \\
\hline
\end{tabular}

Figure 4. Thermocouple arrangement of slab HC25-A2 

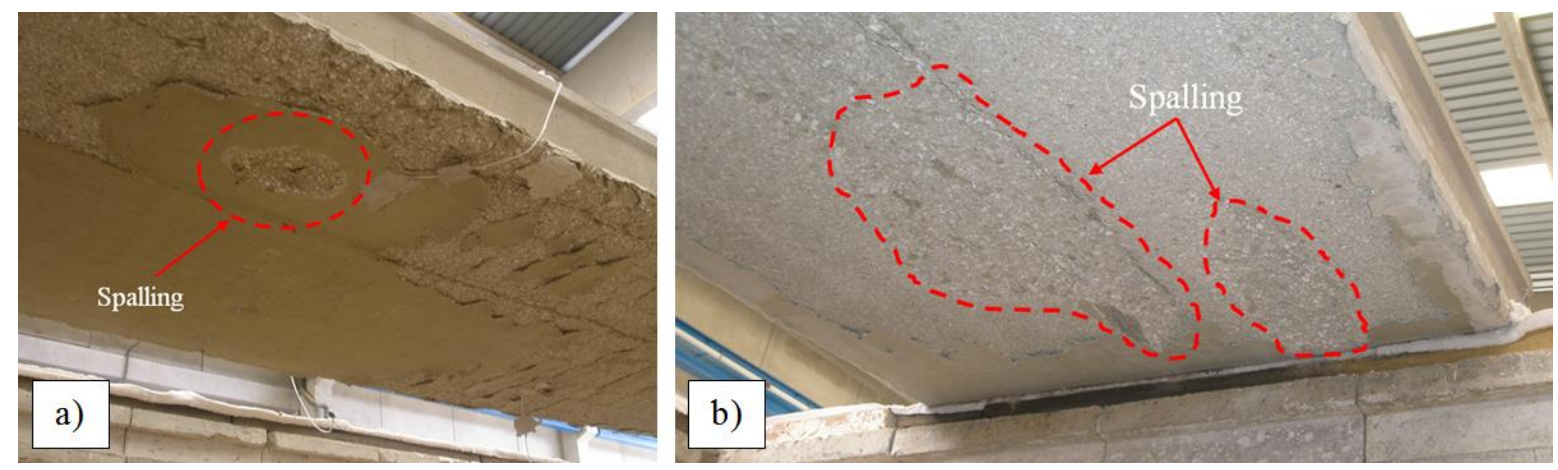

Figure 5. Spalling on the bottom surface of unit HC25-A2: a) Central zone. b) Support zone. 

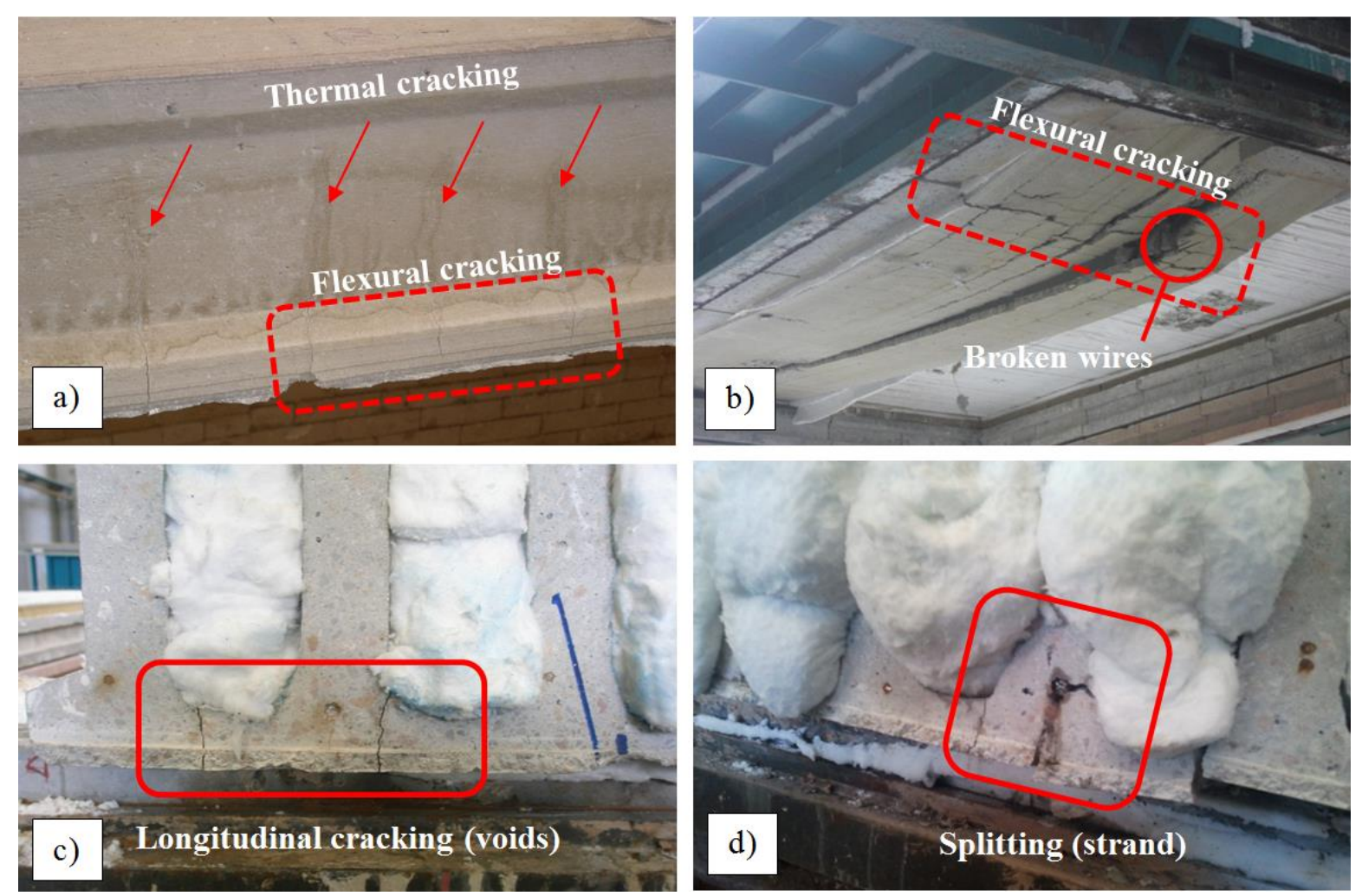

Figure 6. Cracking types: a) Thermal cracking in the web and flexural cracking (HC25-A2). b) Flexural cracking and broken wires from below (HC25-A1). c) Longitudinal cracks through the bottom flange (HC25-A2). d) Splitting around one strand of the HC25-A3 

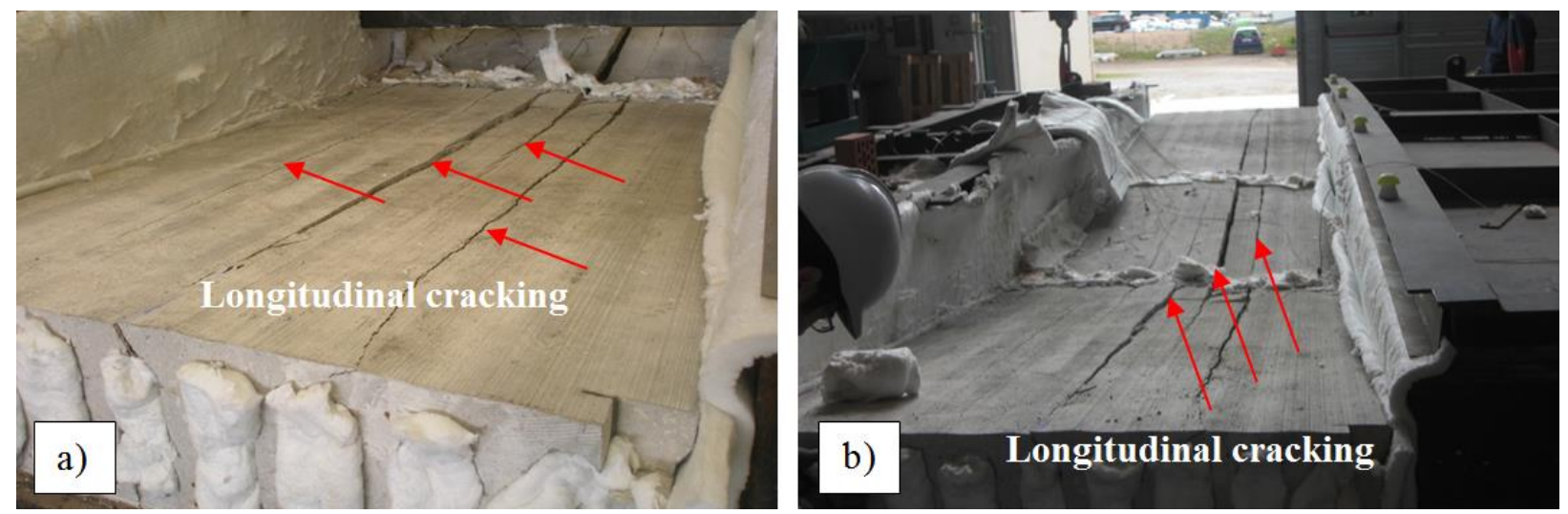

Figure 7.General view after the test. a) Longitudinal cracking of unit HC25-A1. b) Longitudinal cracking of unit HC25-A1. 


\section{o) Wire reinforcement}

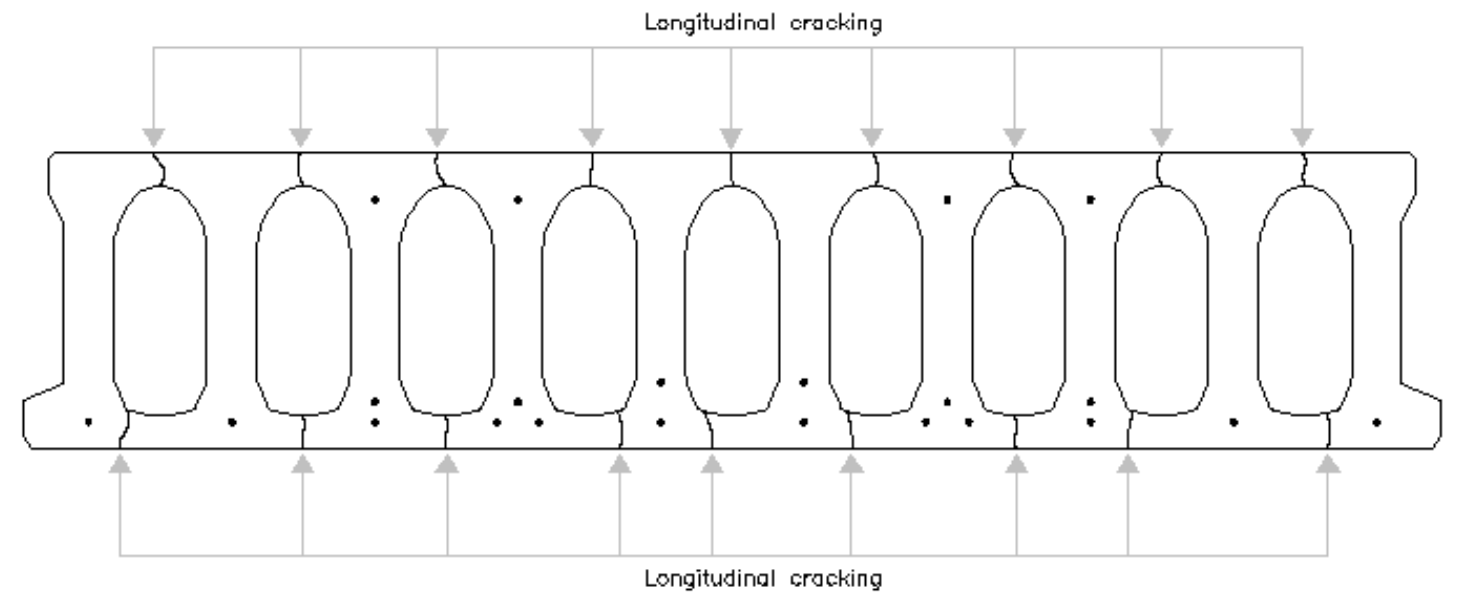

b) Wire/strand reinforcement

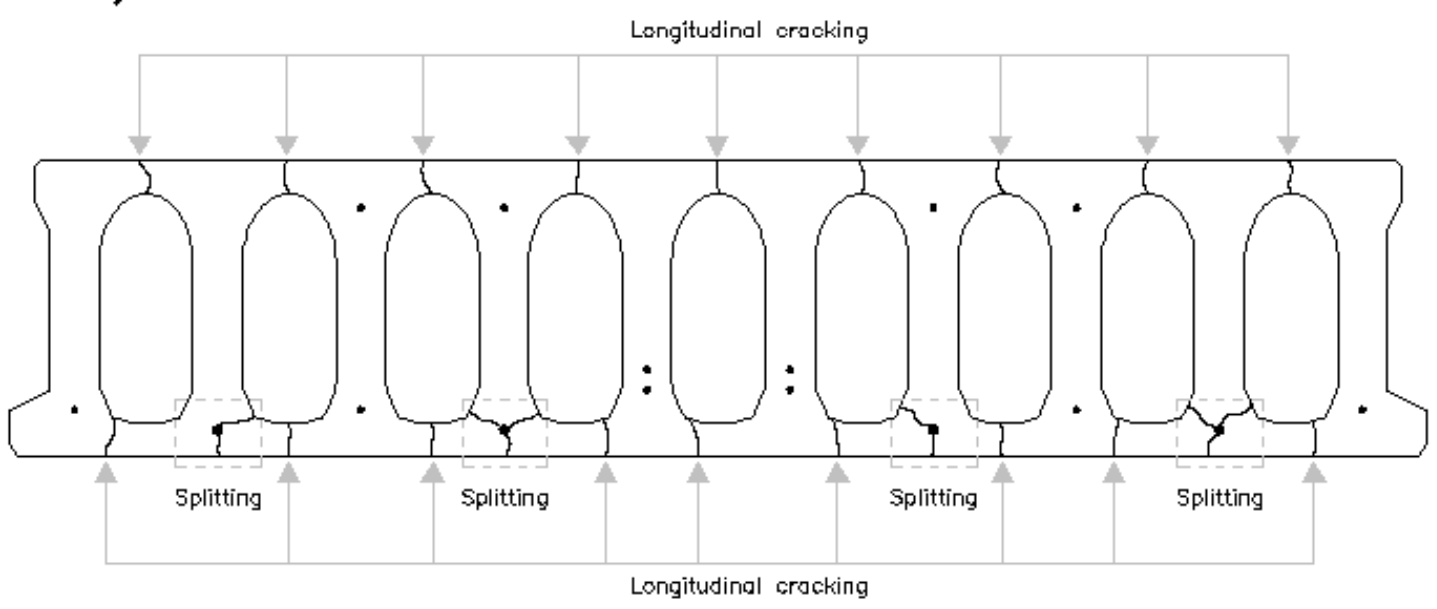

Figure 8. Crack patterns: a) Wire reinforcement. b) Wire/strand reinforcement 
Aguado JV, Espinos A, Hospitaler A, Ortega J, Romero ML. Influence of reinforcement arrangement in flexural fire behavior of hollow core slabs. Fire Saf J. 2012;53:72-84. doi: 10.1016/j.firesaf.2012.06.015

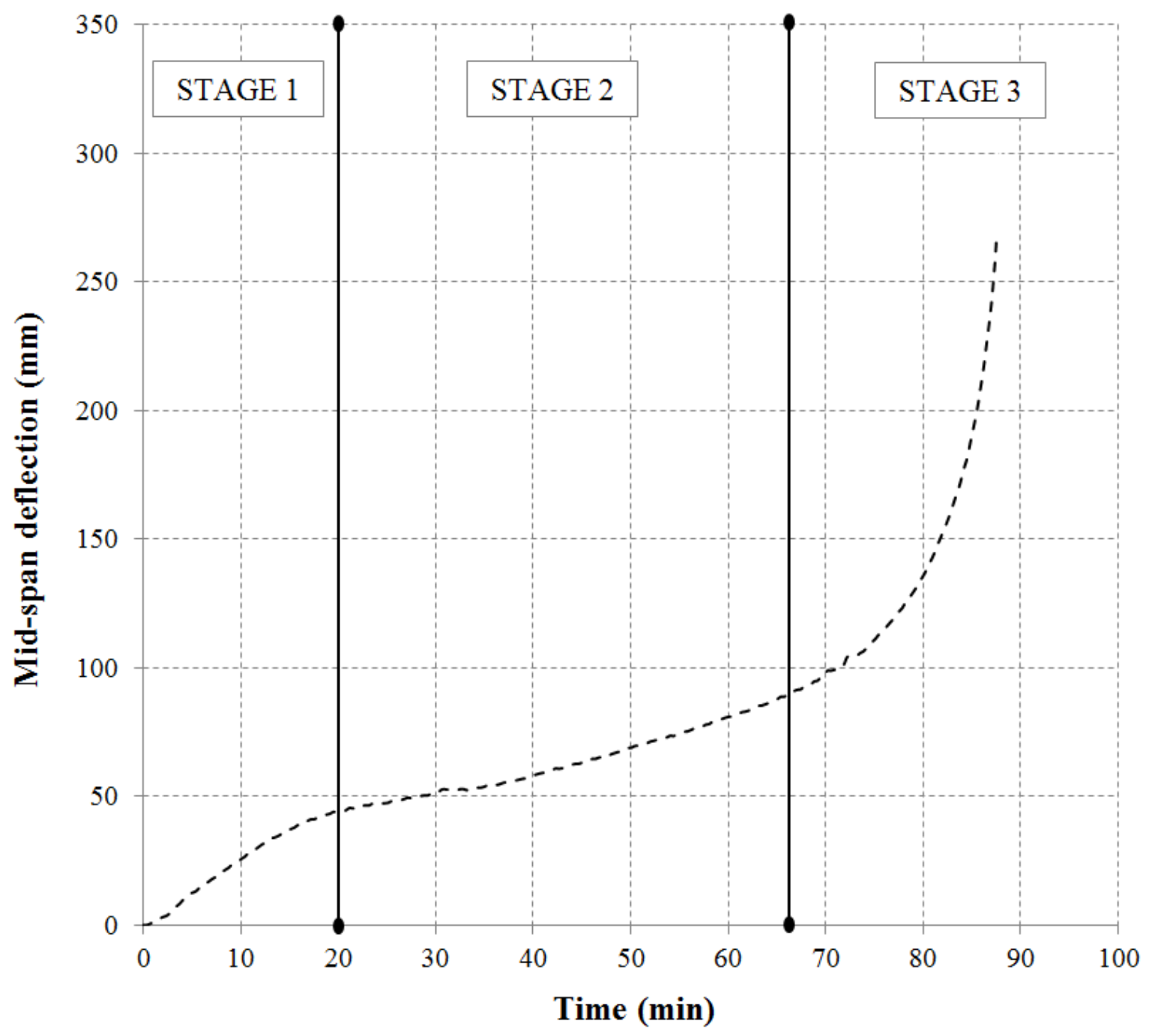

Figure 9.Time versus mid-span deflection. Identification of each stage 


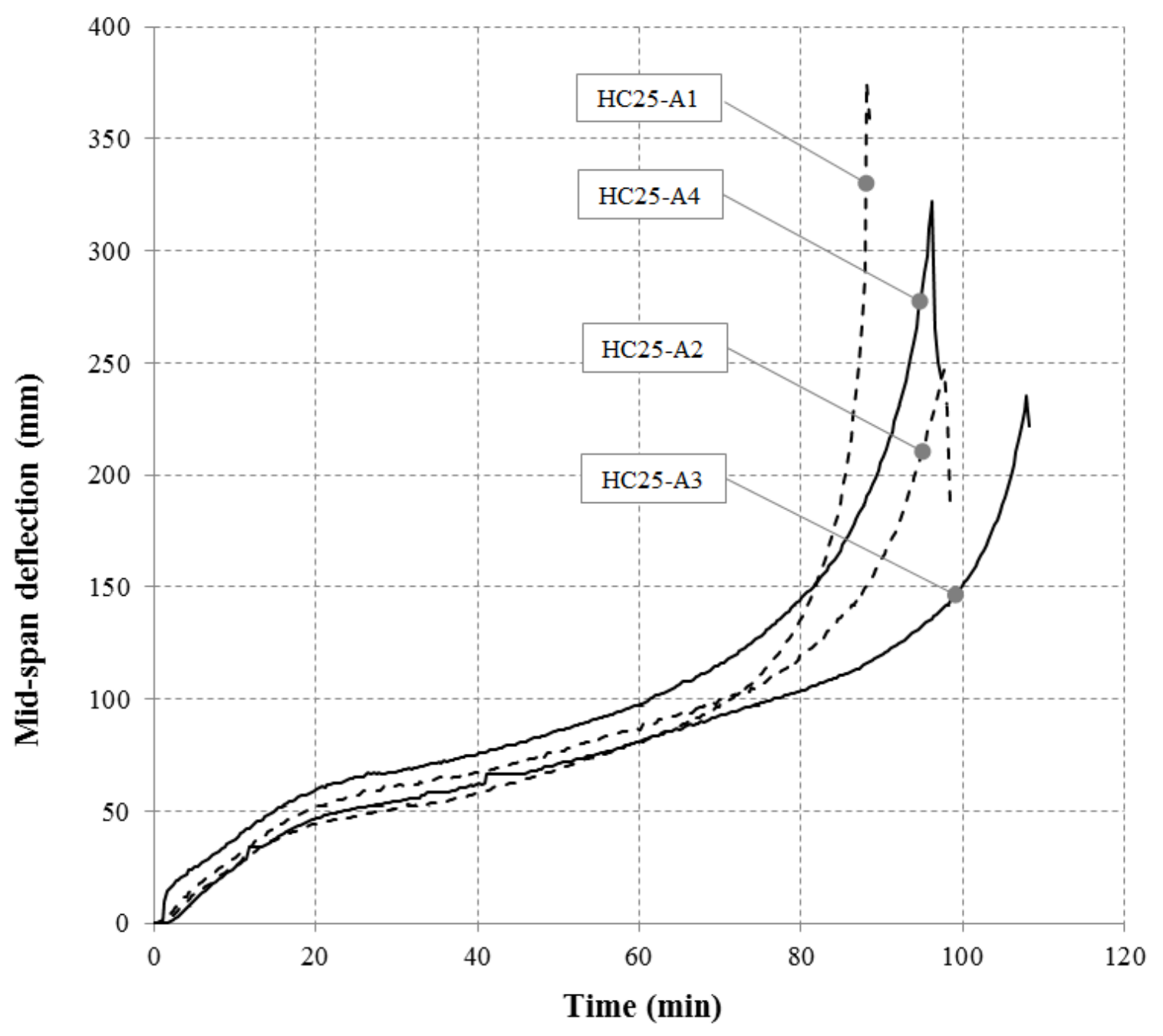

Figure 10. Mid-span deflection of each slab tested. 
Aguado JV, Espinos A, Hospitaler A, Ortega J, Romero ML. Influence of reinforcement arrangement in flexural fire behavior of hollow core slabs. Fire Saf J. 2012;53:72-84. doi: 10.1016/j.firesaf.2012.06.015

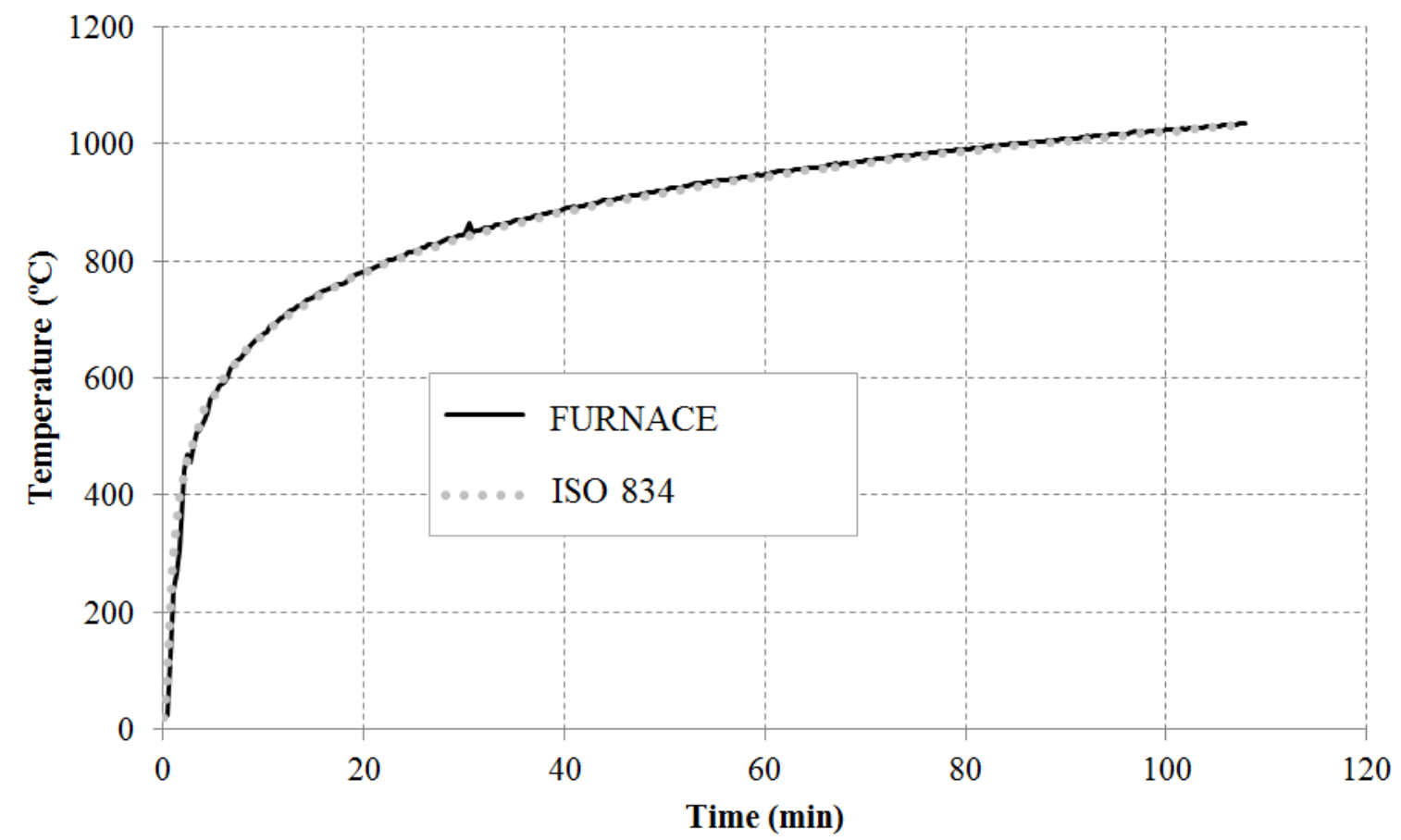

Figure 11. Comparison of the gas temperature inside the furnace with standard fire curve ISO 834 


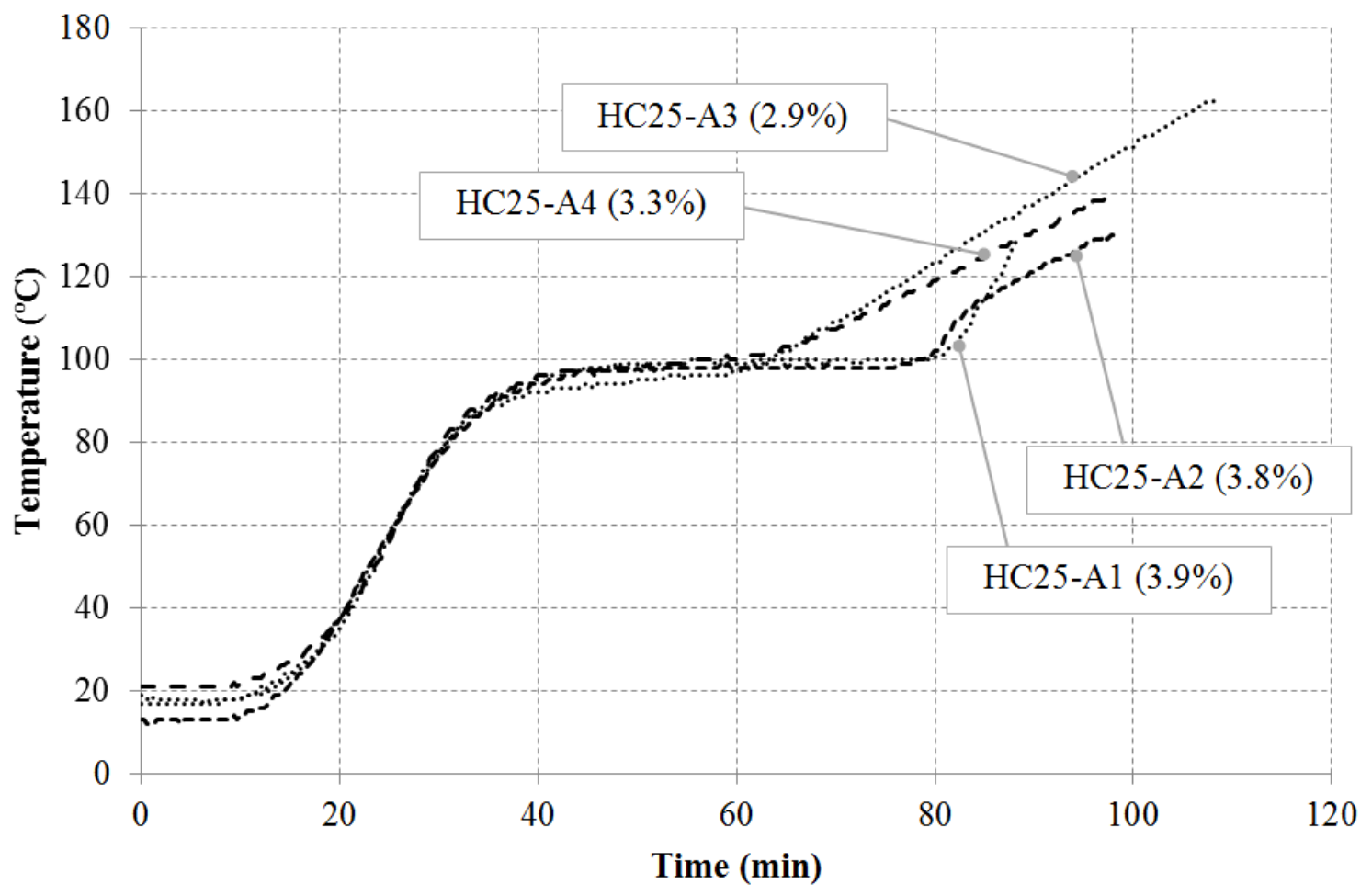

Figure 12. Influence of moisture content. Comparison of thermocouple number 3, located $125 \mathrm{~mm}$ from the exposed surface in each slab. 


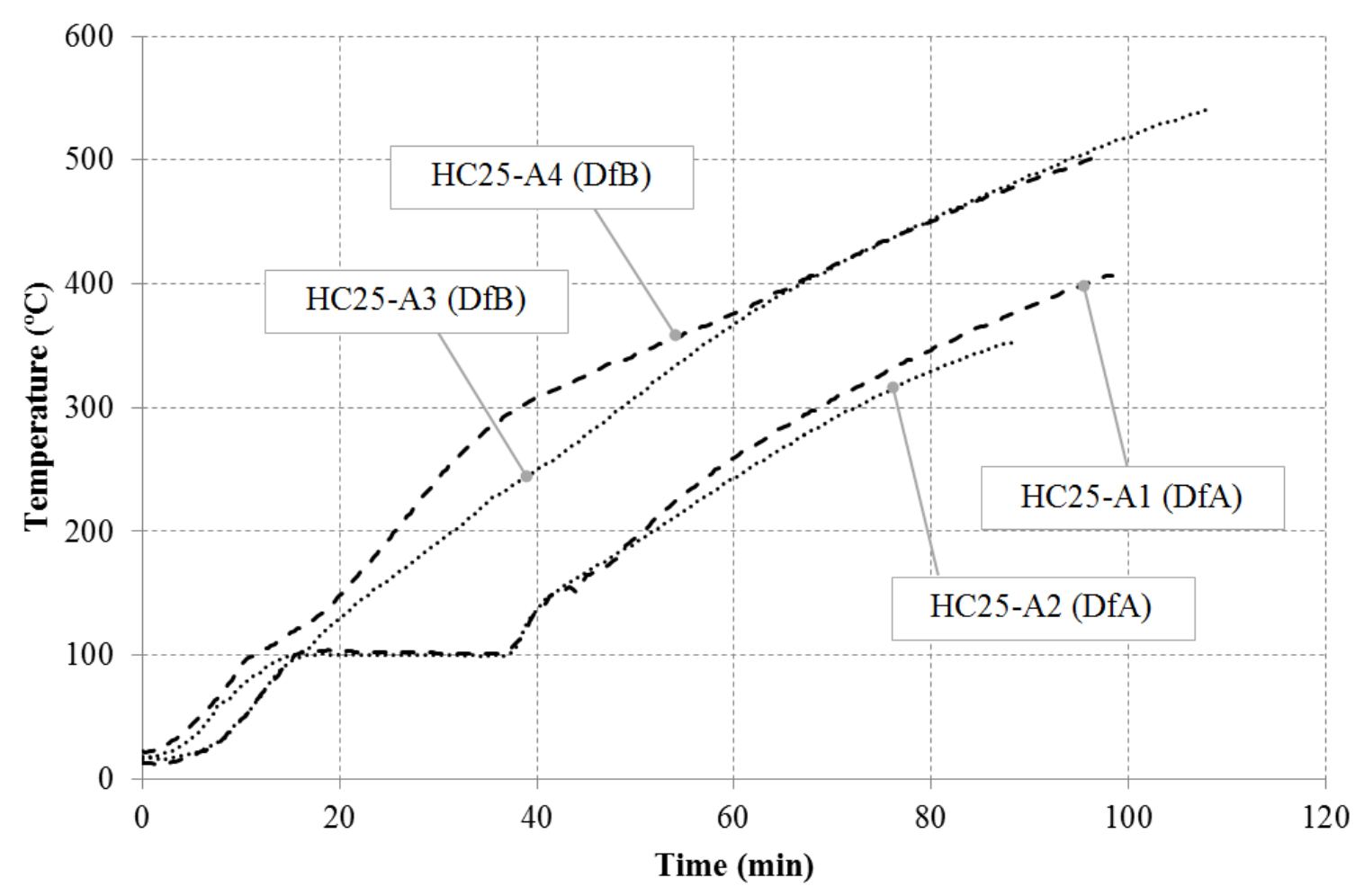

Figure 13. Temperatures at $39.5 \mathrm{~mm}$ from the exposed surface of each slab (Thermocouple number 6). DfA stands for Drilled from Above while DfB stands for Drilled from Below. 
Aguado JV, Espinos A, Hospitaler A, Ortega J, Romero ML. Influence of reinforcement arrangement in flexural fire behavior of hollow core slabs. Fire Saf J. 2012;53:72-84. doi: 10.1016/j.firesaf.2012.06.015
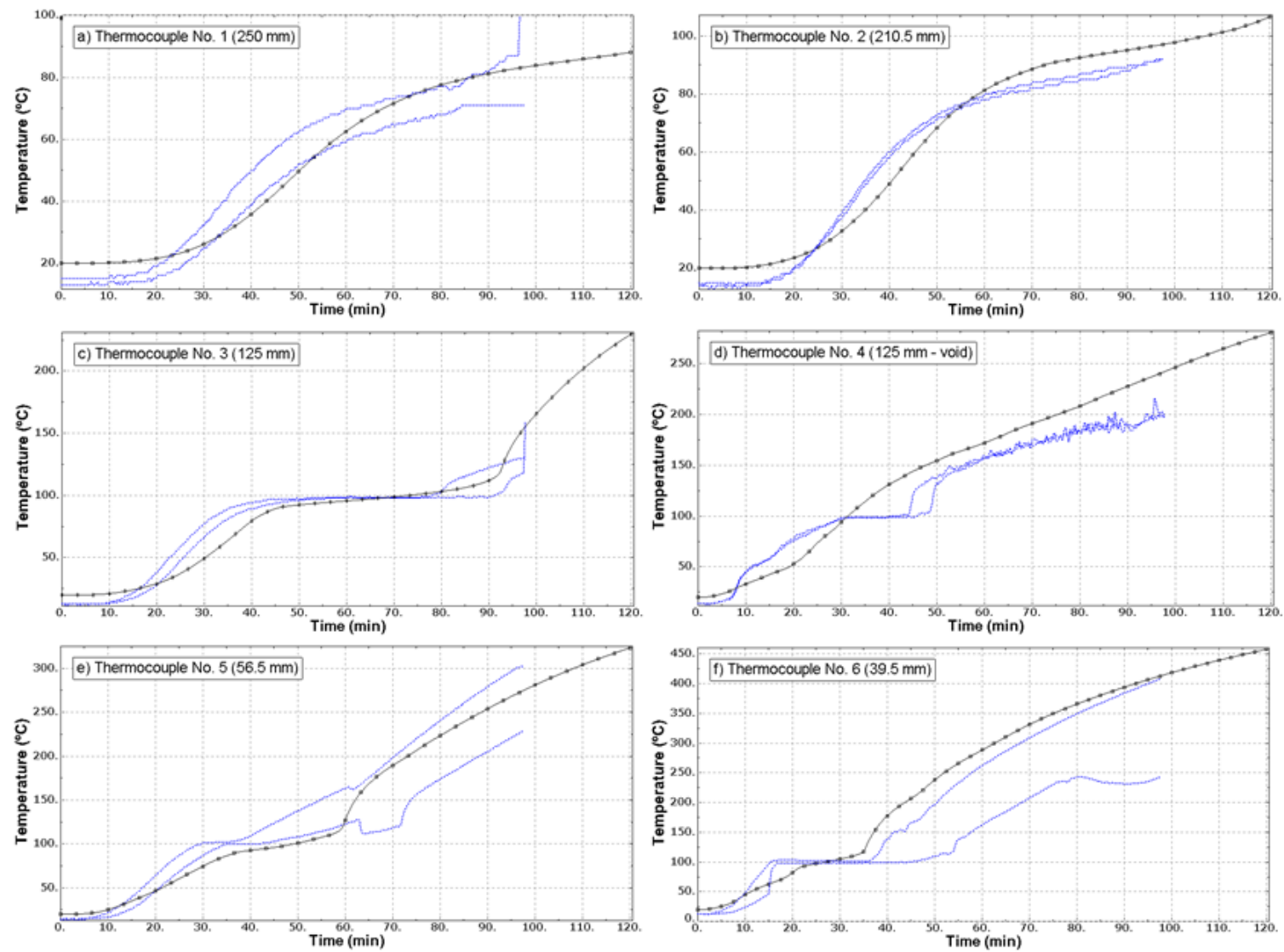

Figure 14. Comparison of measured temperatures for slab HC25-A2 calculated using the numerical model (dotted line). 
Aguado JV, Espinos A, Hospitaler A, Ortega J, Romero ML. Influence of reinforcement arrangement in flexural fire behavior of hollow core slabs. Fire Saf J. 2012;53:72-84. doi: 10.1016/j.firesaf.2012.06.015

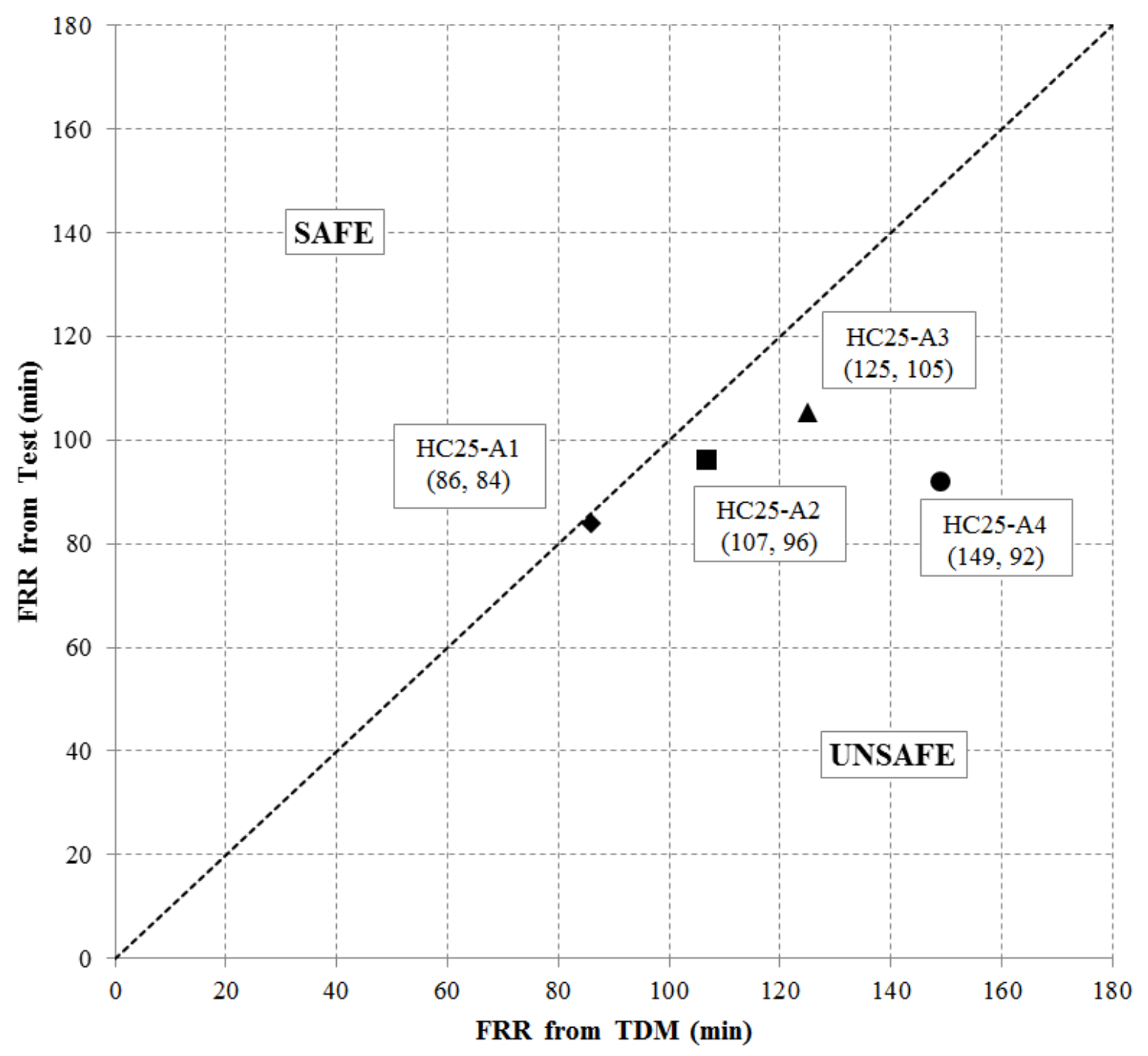

Figure 15. Comparison of Tabulated Data Method with test results 
Aguado JV, Espinos A, Hospitaler A, Ortega J, Romero ML. Influence of reinforcement arrangement in flexural fire behavior of hollow core slabs. Fire Saf J. 2012;53:72-84. doi: 10.1016/j.firesaf.2012.06.015

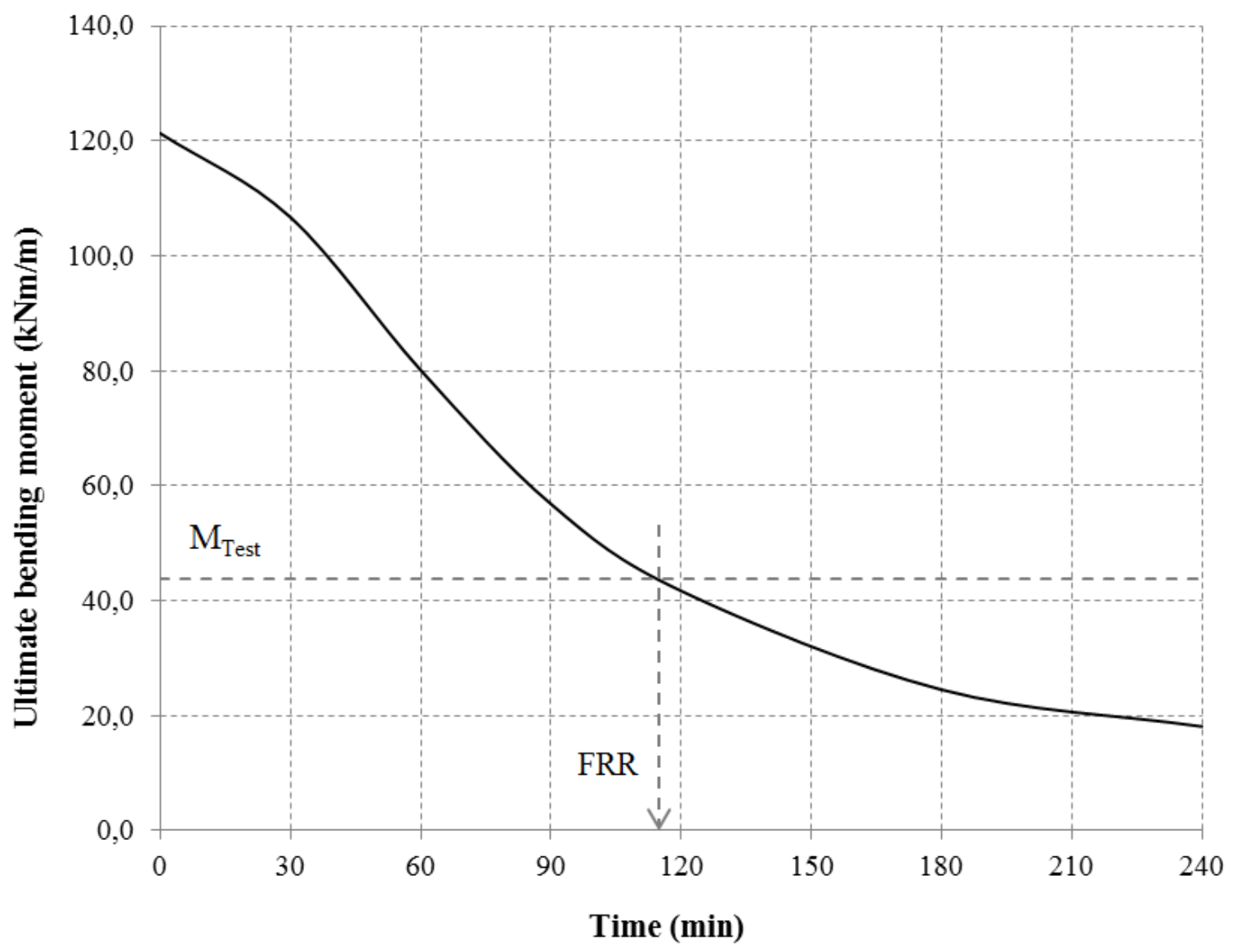

Figure 16. Time of exposure versus ultimate bending moment from the $500^{\circ} \mathrm{C}$ Isotherm Method for obtaining FRR. 


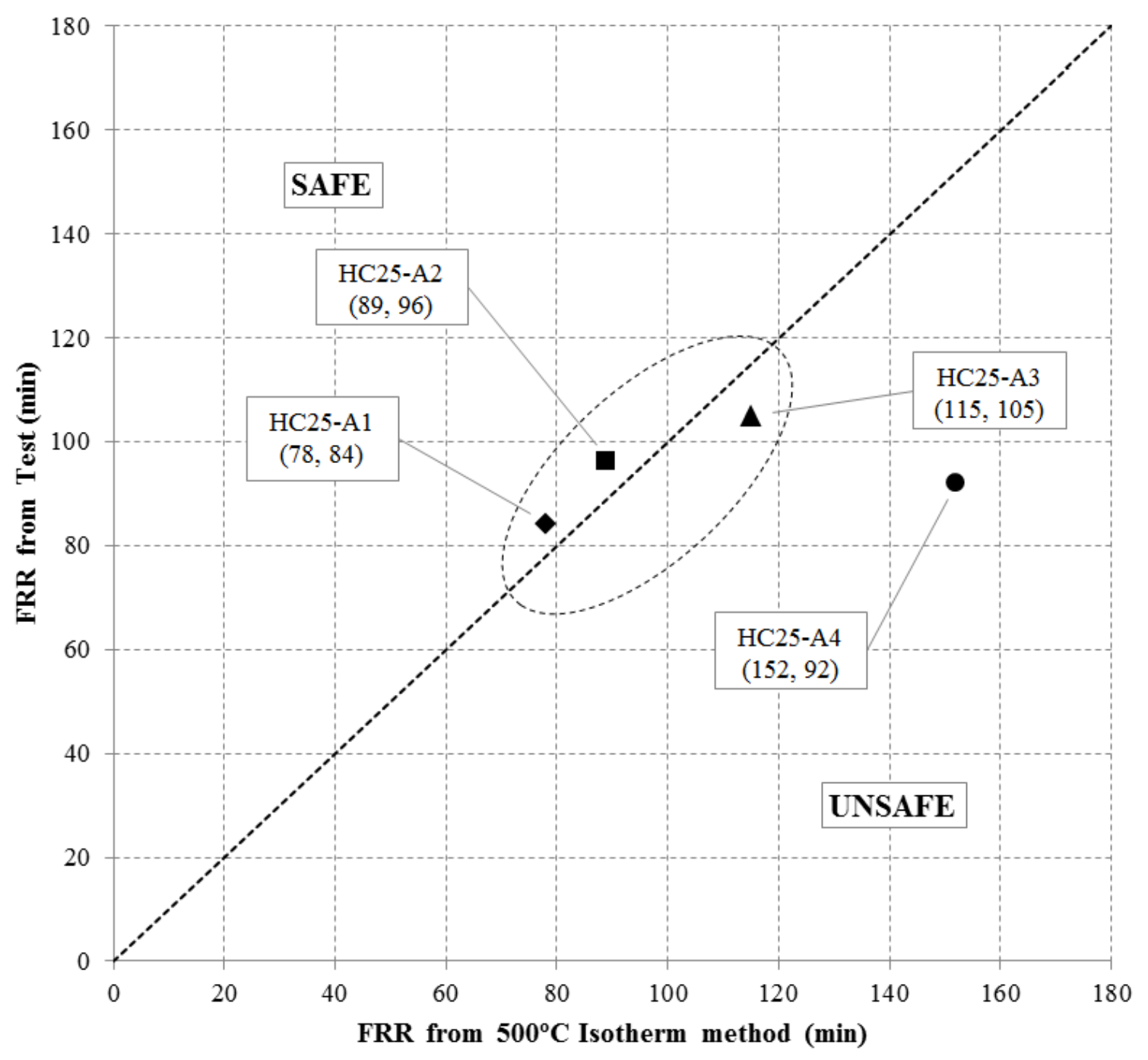

Figure 17. Expected FRR from $500^{\circ} \mathrm{C}$ Isotherm Method versus FRR measured in tests 


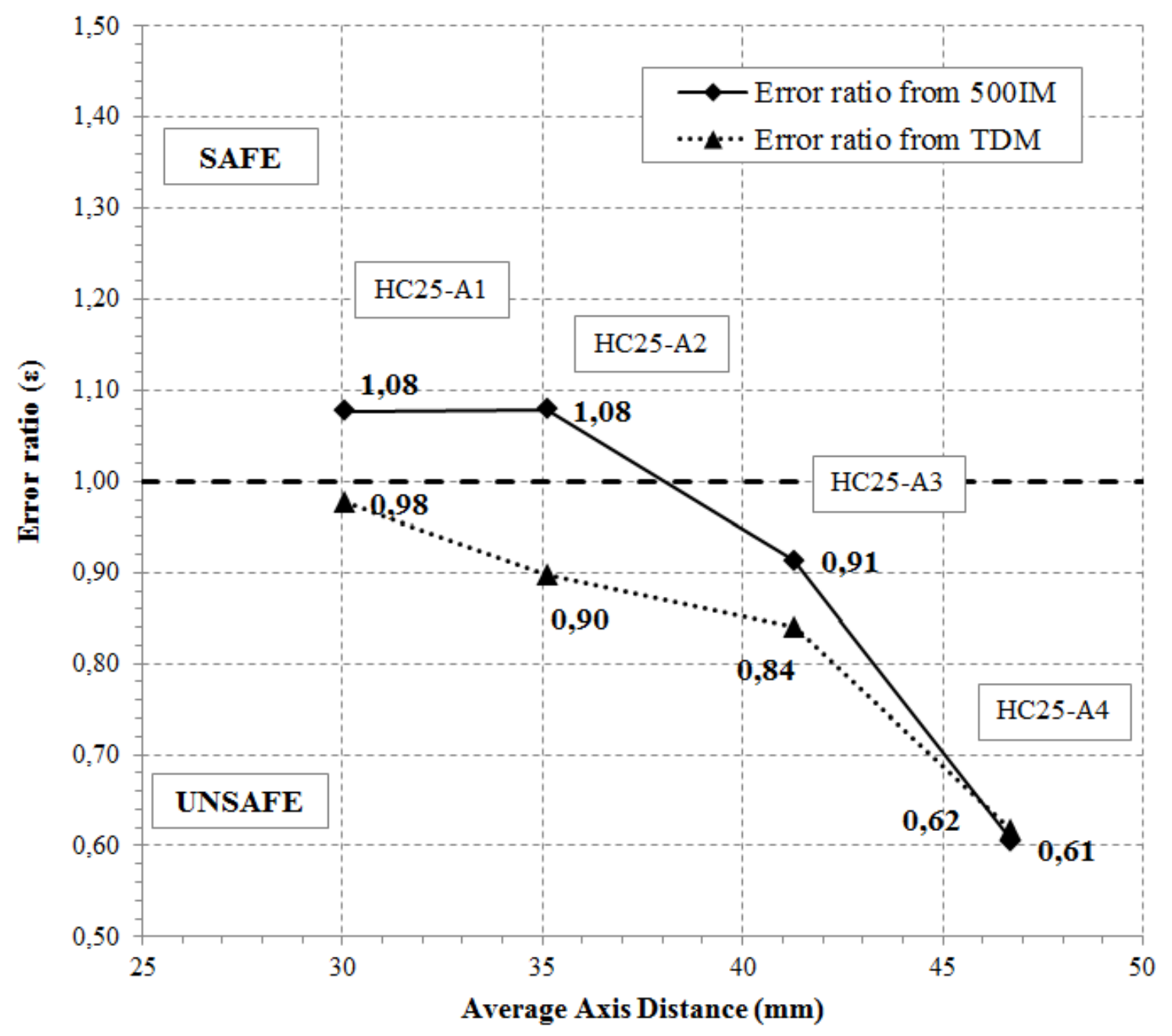

Figure 18. Average axis distance versus error ratio from both Tabulated Data Method and $500^{\circ} \mathrm{C}$ Isotherm Method. 
Table 1. Geometry of tested specimens

\section{Geometric parameters}

\begin{tabular}{lr|lr}
\hline Cross-section height & $250 \mathrm{~mm}$ & No. Voids / Void width & $9 / 79 \mathrm{~mm}$ \\
\hline Cross-section width & $1.20 \mathrm{~m}$ & Void height & $194 \mathrm{~mm}$ \\
\hline Slab length & $5.70 \mathrm{~m}$ & Top flange min. thickness & $28 \mathrm{~mm}$ \\
\hline No. Webs / Web thickness & $10 / 42 \mathrm{~mm}$ & Bottom flange min. thickness & $28 \mathrm{~mm}$ \\
\hline
\end{tabular}

Reinforcement parameters

\begin{tabular}{|c|c|c|c|c|c|c|c|}
\hline & Row 1 & Row 2 & Row 3 & Row 4 & Row 5 & \multirow{2}{*}{$A_{p}\left(m^{2}\right)$} & \multirow{2}{*}{$a_{m}(\mathrm{~mm})$} \\
\hline Axis Dist ${ }^{1}$ & 22.5 & 39.5 & 56.5 & 73.5 & 210.5 & & \\
\hline HC25-A1 & $12 \times \varnothing 5$ & $4 \times \emptyset 5$ & $2 x \emptyset 5$ & -- & $4 \times \varnothing 5$ & 431.9 & 30.1 \\
\hline HC25-A2 & $4 \times \emptyset 3 / 8 "$ & $4 \times \varnothing 5$ & $2 \times \varnothing 5$ & $2 \times \varnothing 5$ & $4 \times \varnothing 5$ & 443.6 & 35.1 \\
\hline HC25-A3 & $4 \times \varnothing 5$ & $4 \times \varnothing 3 / 8 "$ & $2 \times \varnothing 5$ & $2 \times \emptyset 5$ & $4 \times \varnothing 5$ & 443.6 & 41.3 \\
\hline $\mathrm{HC} 25-\mathrm{A} 4$ & -- & $4 \times \varnothing 3 / 8 "$ & $8 \times \varnothing 5$ & -- & $4 \times \varnothing 5$ & 443.6 & 46.7 \\
\hline
\end{tabular}

${ }^{1}$ Axis Distance measured from below.

$3 / 8$ " is equal to $9.5 \mathrm{~mm}$ 
Table 2. Test properties and results

\begin{tabular}{c|c|c|c|c|c|c|c|c|c|c}
\hline No. & Id. & $\begin{array}{c}a_{m} \\
(\mathrm{~mm})\end{array}$ & $\begin{array}{c}\mu_{\exp } \\
(\%)\end{array}$ & $\begin{array}{c}\mathrm{f}_{\mathrm{c}} \\
(\mathrm{MPa})\end{array}$ & $\begin{array}{c}\mathrm{f}_{\mathrm{ct}} \\
(\mathrm{MPa})\end{array}$ & $\begin{array}{c}\text { Moist. } \\
(\%)\end{array}$ & $\begin{array}{c}\text { Drying } \\
(\mathrm{days})\end{array}$ & $\begin{array}{c}\text { Max.D } \\
\text { Max.DR }\end{array}$ & $\begin{array}{c}\text { Limits } \\
\text { reached }\end{array}$ & $\begin{array}{c}\text { FRR } \\
(\mathrm{min})\end{array}$ \\
\hline 1 & HC25-A1 & 30.1 & 36 & 52.1 & 3.50 & 3.90 & 116 & 374.9 & $\mathrm{D}$ & 84 \\
2 & HC25-A2 & 35.1 & 35 & 54.6 & 4.00 & 3.80 & 104 & $\begin{array}{c}247.0 \\
13.8\end{array}$ & DR & 96 \\
\hline 3 & HC25-A3 & 41.3 & 36 & 57.1 & 3.45 & 2.90 & 124 & 235.5 & DR & 105 \\
\hline 4 & HC25-A4 & 46.7 & 37 & 52.4 & 4.05 & 3.30 & 126 & 322.4 & D & 92 \\
\hline
\end{tabular}

D: Deflection ; DR: Deflection Rate

${ }^{1}$ The hydraulic jack reached its maximum displacement, so the test had to be halted. The problem was solved for the other tests (HC25-A2 was tested first). Nevertheless, the slab had already failed before the test was stopped, as the DR limit had been reached. 
Aguado JV, Espinos A, Hospitaler A, Ortega J, Romero ML. Influence of reinforcement arrangement in flexural fire behavior of hollow core slabs. Fire Saf J. 2012;53:72-84. doi: 10.1016/j.firesaf.2012.06.015

Table 3. Spalling events recorded during testing

\begin{tabular}{|c|c|c|c|c|c|c|c|c|}
\hline \multirow{2}{*}{ No. } & \multirow{2}{*}{ Id. } & \multirow{2}{*}{$\begin{array}{c}\text { Moisture } \\
(\%)\end{array}$} & \multirow{2}{*}{$\begin{array}{l}\text { Number } \\
\text { of spalling } \\
\text { cases }\end{array}$} & \multicolumn{5}{|c|}{ Time (min) } \\
\hline & & & & $\begin{array}{l}\text { Spalling } \\
\text { No.1 }\end{array}$ & $\begin{array}{l}\text { Spalling } \\
\text { No.2 }\end{array}$ & $\begin{array}{c}\text { Spalling } \\
\text { No.3 }\end{array}$ & $\begin{array}{c}\text { Spalling } \\
\text { No.4 }\end{array}$ & $\begin{array}{c}\text { Spalling } \\
\text { No.5 }\end{array}$ \\
\hline 1 & HC25-A1 & 3.90 & 2 & 16 & 25 & & & \\
\hline 2 & $\mathrm{HC} 25-\mathrm{A} 2$ & 3.80 & 3 & 17 & 21 & 24 & & \\
\hline 3 & HC25-A3 & 2.90 & 5 & 17 & 19 & 20 & 21 & 24 \\
\hline 4 & HC25-A4 & 3.30 & 4 & 16 & 17 & 18 & 22 & \\
\hline 5 & $\begin{array}{l}\mathrm{HC} 25-\mathrm{A} 4- \\
\text { rep }\end{array}$ & 2.5 & 1 & 40 & & & & \\
\hline
\end{tabular}


Aguado JV, Espinos A, Hospitaler A, Ortega J, Romero ML. Influence of reinforcement arrangement in flexural fire behavior of hollow core slabs. Fire Saf J. 2012;53:72-84. doi: 10.1016/j.firesaf.2012.06.015

Table 4. Results from simplified methods

\begin{tabular}{|c|c|c|c|c|c|c|c|c|c|c|}
\hline \multirow{3}{*}{ No. } & \multirow{3}{*}{ Id. } & \multicolumn{5}{|c|}{ Tabulated Data Method } & \multicolumn{4}{|c|}{$500^{\circ} \mathrm{C}$ Isotherm Method } \\
\hline & & \multirow{2}{*}{$\begin{array}{l}\theta_{c r} \\
(\%)\end{array}$} & \multirow[b]{2}{*}{$\begin{array}{c}\Delta a \\
(\mathrm{~mm})\end{array}$} & \multirow[b]{2}{*}{$\begin{array}{c}a_{m} \\
(\mathrm{~mm})\end{array}$} & \multirow[b]{2}{*}{$\begin{array}{c}F R R_{T D M} \\
(\min )\end{array}$} & \multirow[b]{2}{*}{$\varepsilon_{T D M}$} & \multicolumn{2}{|c|}{ Temperature from EC2 } & \multicolumn{2}{|c|}{ Temperature from FEM } \\
\hline & & & & & & & $\begin{array}{c}F R R_{500 I M} \\
(\min )\end{array}$ & $\varepsilon_{500 I M}$ & $\begin{array}{c}F R R_{500 I M} \\
(\min )\end{array}$ & $\varepsilon_{500 I M}$ \\
\hline 1 & HC25-A1 & 469 & 4 & 30.1 & 86 & 0.98 & 75 & 1.12 & 78 & 1.08 \\
\hline 2 & $\mathrm{HC} 25-\mathrm{A} 2$ & 473 & 3 & 35.1 & 107 & 0.90 & 88 & 1.09 & 89 & 1.08 \\
\hline 3 & $\mathrm{HC} 25-\mathrm{A} 3$ & 469 & 4 & 41.3 & 125 & 0.84 & 115 & 0.91 & 115 & 0.91 \\
\hline 4 & $\mathrm{HC} 25-\mathrm{A} 4$ & 466 & 4 & 46.7 & 149 & 0.62 & 140 & 0.66 & 152 & 0.61 \\
\hline 5 & $\begin{array}{l}\mathrm{HC} 25-\mathrm{A} 4- \\
\text { rep }\end{array}$ & 466 & 4 & 46.7 & 149 & 0.62 & 140 & 0.69 & 152 & 0.64 \\
\hline
\end{tabular}

